\title{
O DESAFIO DA ATIVAÇÃO DAS LIGAÇÕES C-H EM SÍNTESE ORGÂNICA
}

\author{
Francisco de Azambuja e Carlos Roque Duarte Correia*
}

Instituto de Química, Universidade Estadual de Campinas, CP 6154, 13084-971 Campinas - SP, Brasil

Recebido em 11/3/11; aceito em 9/6/11; publicado na web em 9/8/11

\begin{abstract}
THE CHALLENGE OF C-H ACTIVATION IN ORGANIC SYNTHESIS. This review aims at to the presentation and discussion of the principal aspects of the $\mathrm{C}-\mathrm{H}$ activation by transition metals. Representative examples were selected from the recent literature to illustrate these principles beginning with somewhat simple examples and moving up to more complex ones. The synthetic potential of the $\mathrm{C}-\mathrm{H}$ activation, as well as the potential advantages and disadvantages of the methodology are highlighted with relevant recent examples, along with brief insights on the mechanism aspects of these reactions.
\end{abstract}

Keywords: C-H activation; transition metals; organic synthesis.

Em linhas gerais, para que uma reação orgânica aconteça é preciso que haja uma ligação química suscetível, de forma geral, à clivagem, migração, substituição e/ou adição. Naturalmente, tal ocorrência é induzida por um agente externo, seja ele uma molécula, uma fonte de energia, ou até mesmo outra parte da mesma molécula. Frequentemente, a ligação química em questão é relativamente ativada, isto é, possui patamar energético relativamente elevado, o que facilita sua manipulação sintética. Logo, é desejável que os substratos envolvidos em uma reação sejam previamente funcionalizados, ou seja, contenham sítios reacionais cuja natureza seja suscetível às condições do meio reacional.

Frequentemente, utiliza-se o termo "ativação" para designar o aumento da reatividade de uma ligação/molécula frente a algum reagente ou condição reacional. Em muitos casos, o termo "ativação" implica na ruptura da ligação química. O principal resultado da ativação de uma ligação C-H é a sua substituição por uma ligação mais fraca/mais funcionalizada (i.e., mais suscetível a outras reações). Por exemplo, um composto insaturado pode ser ativado mediante coordenação a um centro metálico dos seus orbitais $\pi$. Entretanto, para um composto saturado esta rota não é possível e outros mecanismos devem ser utilizados. ${ }^{1}$

Sobre as ligações C-H e a sua ativação, três informações básicas precisam ser previamente fornecidas: a ligação carbono-hidrogênio é uma das mais estáveis que existem, isto é, é termodinamicamente estável e cineticamente inerte; é uma ligação onipresente em compostos orgânicos; o maior estoque de moléculas orgânicas são as reservas de petróleo e gás natural, ou seja, a vasta maioria das matérias-primas da química são hidrocarbonetos. Logo, a ativação da ligação carbonohidrogênio (ativação C-H) não é nova. ${ }^{1}$ Pelo contrário, a humanidade ainda estaria nos primórdios da evolução tecnológica caso não houvessem desenvolvimentos nesta área.

$\mathrm{O}$ aproveitamento mais direto dos hidrocarbonetos, particularmente dos alcanos, é proporcionado pelo oxigênio, pois estes sofrem, a temperaturas devidas, oxidação completa, ou queima, fornecendo água, dióxido de carbono e muito calor. No entanto, à temperatura ambiente, sem a presença de um catalisador, os alcanos são praticamente inertes ao oxigênio atmosférico. Esta dicotomia, relacionada aos alcanos, expõe claramente o desafio geral da ativação de ligações

*e-mail: roque@iqm.unicamp.br
C-H. Via de regra, a condição reacional para a funcionalização das ligações $\mathrm{C}-\mathrm{H}$ de alcanos deve ser agressiva/drástica (aquecimento, craqueamento, etc). Os hidrocarbonetos insaturados têm aproveitamento mais fácil, pois são suscetíveis a reações em suas ligações $\pi$, muito mais reativas que as ligações $\sigma \mathrm{C}$-H. Exemplos de reações de suas próprias ligações C-H são mais raros (posições alílicas, por exemplo).

Uma alternativa bem estabelecida para dar outros destinos aos hidrocarbonetos, que não o de combustível, são as reações radicalares. Os radicais orgânicos são bastante conhecidos na química e têm estabilidades e reatividades características. Estas propriedades conferem às reações radicalares características próprias de seletividade e são, sem sombra de dúvida, uma vertente importante da química como um todo. ${ }^{2}$ Apesar de todo esse conhecimento sobre como aproveitar a reserva primária de compostos orgânicos, transformações alternativas ainda são buscadas para melhorar rendimento e seletividade, aprimorando a eficiência de processos responsáveis por tornar mais utilizáveis o que a natureza nos oferece. ${ }^{3,4}$

Nos últimos anos tem se destacado a ideia de que estas ligações C-H são também precursores viáveis para diversos grupos funcionais, através de reações catalisadas por metais de transição. Nas últimas duas décadas, diversas metodologias que empregam estes metais foram desenvolvidas para a formação de novas ligações C-C, C-N, C-O, C-B, dentre outras. ${ }^{5}$

Neste sentido, o presente texto visa proporcionar uma reflexão acerca das metodologias aplicadas recentemente para a funcionalização direta das ligações C-H no contexto de desenvolvimento metodológico e aplicação na síntese de substâncias orgânicas complexas. ${ }^{6}$ Sendo assim, serão discutidas algumas alternativas promissoras e inovadoras à "química orgânica sintética tradicional", além dos aspectos pertinentes sobre o mecanismo e a seletividade desses processos.

\section{INOVAÇÃO: PORQUE A ATIVAÇÃO C-H VEM TRANSFORMANDO A QUÍMICA ORGÂNICA SINTÉTICA}

A ativação C-H catalisada por metais de transição ainda é um método no início de seu desenvolvimento. A possibilidade de trocar a ligação C-H "inerte" diretamente por outro grupo funcional, questiona diretamente os paradigmas atuais da síntese orgânica e tem incentivado um grande número de publicações sobre o tema. É importante frisar que não se trata de abandonar os sólidos conceitos construídos 
até hoje, mas sim de buscar alternativas mais diretas para a síntese de compostos orgânicos com crescente complexidade estrutural.

Por exemplo, as reações de acoplamentos cruzados são hoje uma rotina dentro da síntese orgânica. ${ }^{7}$ Dentre tais transformações, a reação de Suzuki-Miyaura se destaca como uma das principais, por sua versatilidade e confiabilidade, principalmente na obtenção de sistemas biarílicos assimétricos. Esta reação consiste no acoplamento de um ácido borônico arílico ou vinílico com um haleto de arila na presença de paládio, formando a nova ligação $\mathrm{C}\left(\mathrm{sp}^{2}\right)-\mathrm{C}\left(\mathrm{sp}^{2}\right)$. Em 2010, Liu e colaboradores $^{8}$ relataram um sistema catalítico bimetálico de cobre (I) e paládio para a arilação direta de heteroaromáticos imidazólicos e análogos, utilizando ácidos borônicos como agentes arilantes (Esquema 1). Nestes acoplamentos, os autores sugeriram que o sal de cobre (I) foi o responsável pela ativação C-H na porção imidazólica e que por transmetalação este grupo é transferido à esfera de coordenação do paládio. O sal de cobre (II) foi empregado apenas como oxidante do paládio zerovalente formado ao final da reação. Com esta abordagem, os autores eliminaram a necessidade do haleto aromático para a preparação do mesmo produto pela reação de Suzuki-Miyaura.
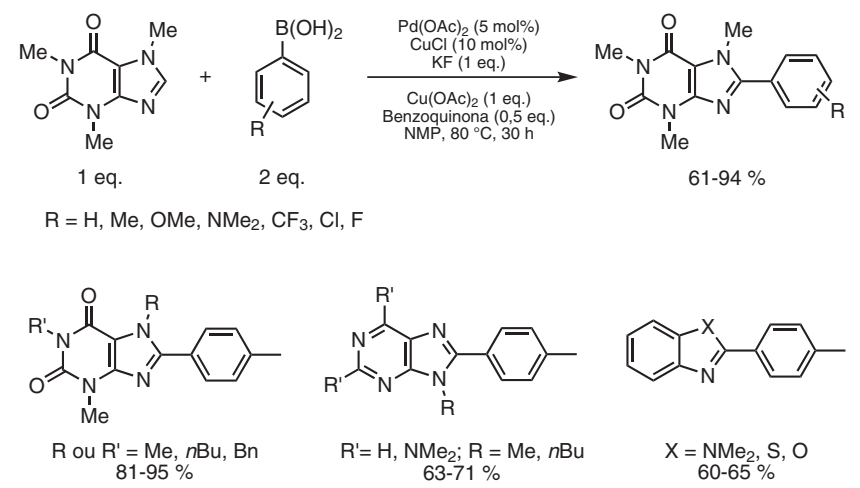

Esquema 1. Arilação direta de sistemas imidazólicos com ácidos borônicos

Os autores ainda estenderam as condições reacionais desenvolvidas para a arilação de indolizidinas e compararam com um procedimento descrito previamente na literatura. ${ }^{9}$ Entre as vantagens da arilação direta estão a economia de uma etapa de reação, a praticidade experimental, a economia do reagente utilizado na cloração, a diminuição da geração de resíduos das etapas de isolamento e purificação e o maior rendimento global, i.e., 64\% para a rota de Liu e colaboradores contra $51 \%$ de rendimento global da rota descrita anteriormente na literatura, embora esta comparação não seja totalmente válida por se tratarem de agentes arilantes distintos (Esquema 2). De qualquer forma, há um claro reconhecimento de que a arilação de Liu e colaboradores apresenta diversas vantagens quando comparada a outras metodologias, apesar da generalidade deste novo método não ter sido plenamente testada.

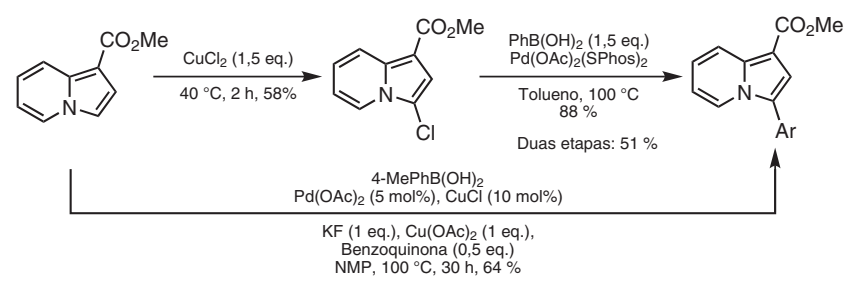

Esquema 2. Comparação entre a ativação C-H e a reação de Suzuki-Miyaura para a arilação de indolizidinas

A arilação direta, introduzida no exemplo acima, é uma das portas de entrada do desenvolvimento metodológico inerente às ativações C-H. Em linhas gerais, três maneiras de preparação de biarilas são factíveis: uso de dois reagentes pré-funcionalizados $;{ }^{10}$ emprego de um reagente pré-funcionalizado e outro não pré-funcionalizado (requerendo uma ativação $\mathrm{C}-\mathrm{H}$ ); utilização de dois arenos não ativados (requerendo duas ativações C-H). Esta última forma é a ideal, porém a mais difícil de ser concretizada. ${ }^{11}$ Por essa razão, o termo "arilação direta" tem sido descrito na literatura como o acoplamento entre um areno funcionalizado e outro não funcionalizado. ${ }^{12,13}$

Dentre as comunicações recentes sobre o tema, ${ }^{14}$ os cloretos de arila são frequentemente utilizados como agentes arilantes. Estes haletos orgânicos são os menos reativos de sua série, mas são também os mais baratos, justificando assim o esforço de levar a metodologia até sua aplicação final. Roy e colaboradores, ${ }^{15}$ por exemplo, realizaram a arilação de diversos anéis heteroaromáticos na presença de $0,5 \mathrm{~mol} \%$ de $\mathrm{Pd}(\mathrm{OAc})_{2}$ e de um ligante do tipo fosfina. As reações foram feitas em $\mathrm{N}, \mathrm{N}$-dimetilacetamida (DMAc), com aquecimento a $150{ }^{\circ} \mathrm{C}$ por $16 \mathrm{~h}$. Os rendimentos variaram entre 15 e $93 \%$, para os diversos casos (Esquema 3).

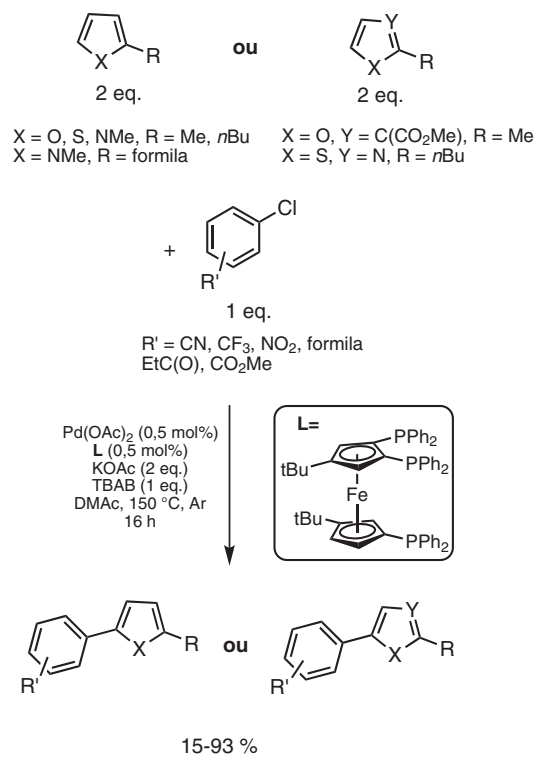

Esquema 3. Arilação direta de anéis heteroaromáticos com cloretos de arila catalisada por paládio

$\mathrm{Na}$ mesma linha, Arockiam e colaboradores ${ }^{16}$ desenvolveram condições para arilação direta catalisada por rutênio (II) em água com cloretos heteroaromáticos (Esquema 4). O melhor desempenho dos cloretos em comparação com os brometos e iodetos foi atribuído à sua maior solubilidade em água, solvente que se mostrou mais eficiente do que os solventes orgânicos. Após a avaliação metodológica, os autores demonstraram a aplicação do novo método na síntese de compostos poliaromáticos em apenas uma etapa. Os produtos obtidos podem ser utilizados como ligantes polidentados, cuja importância em catálise é crescente, ou então na composição de novos materiais com propriedades ópticas.

Dentre os diversos pesquisadores que se dedicaram ao tema de formação de ligação entre anéis aromáticos e/ou heteroaromáticos, Keith Fagnou foi um dos que mais contribuíram. ${ }^{17}$ Além de ter sido um dos primeiros a colocar este campo de pesquisa novamente em evidência, foi quem primeiro tornou pública a possibilidade de arilação direta usando como agente arilante anéis aromáticos não ativados, isto é, não pré-funcionalizados. ${ }^{18}$ Esta ideia aparentemente simples requisitou concentrações elevadas de paládio, um grande excesso de agente arilante e oxidante metálico, aquecimento a $140{ }^{\circ} \mathrm{C}$ e tempo reacional de 5-24 h (Esquema 5). A maior seletividade em favor do produto A não foi totalmente esclarecida. 
<smiles>c1ccc(-c2cccnc2)cc1</smiles><smiles>[R]c1ccc(Cl)nc1</smiles>

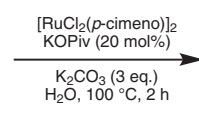

1 eq.

$$
2,5 \text { eq. }
$$

$$
\begin{array}{ll}
X=C, n=1 & Y=S, R=H, M e, n=1 \\
X=N, n=0 & Y=N, R=H, M e, n=2 \\
& Y=C, R=H, n=2
\end{array}
$$<smiles>Clc1cc(Cl)cc(Cl)c1</smiles>

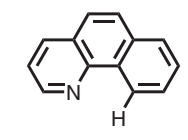

1 eq.
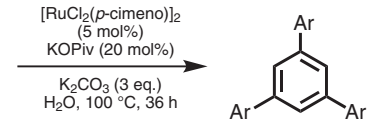

$45-77 \%$

3,2 eq.

Esquema 4. Arilação direta com cloretos de (hetero)arila catalisada por rutênio

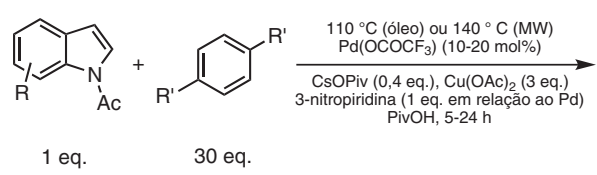

$\mathrm{R}=\mathrm{H}, \mathrm{Cl}, \mathrm{Me}, \mathrm{OMe}, \mathrm{CO}_{2} \mathrm{Me}$

$\mathrm{R}^{\prime}=\mathrm{H}, \mathrm{Me}, \mathrm{OMe}, \mathrm{F}$

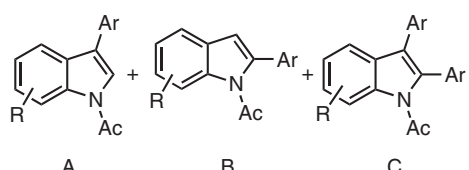

A

B

Rend.: $42-84 \%$

Conversão: $72-100 \%$
A:B:C $=\mathbf{2 , 8 : 1 : 0}\left(\mathrm{R}=\mathrm{CO}_{2} \mathrm{Me}, \mathrm{R}^{\prime}=\mathrm{H}\right)$

$-11,2: 1: 0,4\left(R=O M e, R^{\prime}=H\right)$

Esquema 5. Formação de sistemas biarílicos a partir de dois arenos não pré-funcionalizados

Apesar das condições reacionais não muito atrativas, alguns autores logo se utilizaram destes novos conceitos para preparar moléculas bioativas. Por exemplo, Shi e colaboradore ${ }^{19}$ estudaram a arilação direta de uma acetanilida cíclica, na presença de excesso do agente arilante (Esquema 6A). Essa metodologia foi usada na preparação da 4-desoxicarbazomicina $\mathrm{B}^{20}$ a partir do benzeno e da acetanilida substituída através de três ativações $\mathrm{C}-\mathrm{H}$ (duas na condição desenvolvida neste estudo e outra nas condições de Buchwald, ${ }^{21}$ Esquema 6B).

Outro exemplo pertinente que demonstra a inovação proposta pelas ativações $\mathrm{C}-\mathrm{H}$ vem da cicloaromatização de alcinos para a produção de naftalenos e antracenos, estudada no final da década de 1990 pelos grupos de Miura ${ }^{22}$ e de Guitián e Perez. ${ }^{23}$ Estes grupos desenvolveram sínteses destes compostos a partir de precursores de benzinos do tipo sililaril triflatos. ${ }^{24}$ Recentemente, algumas abordagens a partir de um anel aromático mono funcionalizado foram descritas, eliminando a necessidade de uma fonte de fluoreto e o consequente resíduo gerado pelo grupo trimetilsilila. ${ }^{25}$ Avanço maior foi descrito por Wu e colaboradores,$^{26}$ no qual a preparação de naftalenos é feita a partir de $p$-xileno ou outros benzenos substituídos e alcinos, mediante duas ativações C-H (Esquema 7). ${ }^{27}$

Estes exemplos ilustram muito bem as limitações e os avanços inerentes à ativação da ligação $\mathrm{C}$-H. O principal desafio, uma vez que a clivagem da ligação C-H se mostrou possível, é o da seletividade. Natural que assim seja, visto que mesmo um simples anel aromático

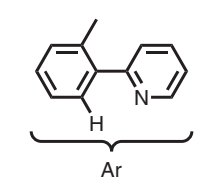

B)

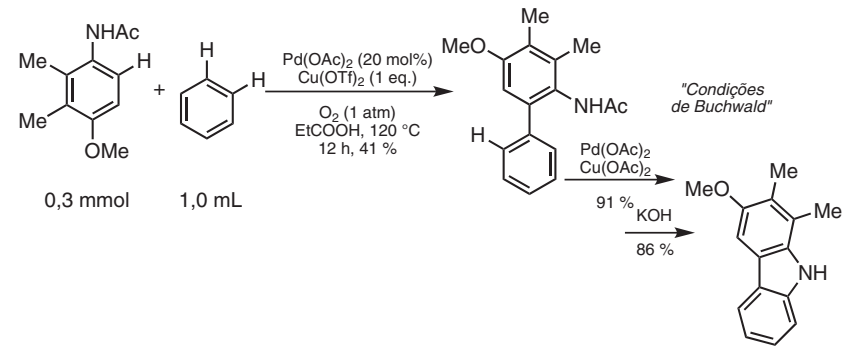

4-desoxicarbazomicina B

Esquema 6. Arilação direta de acetanilidas com agentes arilantes não funcionalizados e aplicação na síntese da 4-desoxicarbazomicina $B$<smiles>[R]c1ccccc1</smiles>

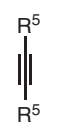

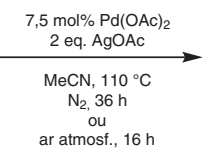

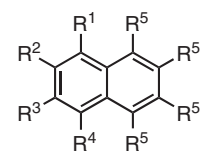

$R^{1}, R^{2}, R^{3}, R^{4}=H$, alquila, cicloalquila, $\mathrm{OMe}, \mathrm{Cl}$ e/ou $\mathrm{Br}$

$6-60 \%$ 30 exemplos

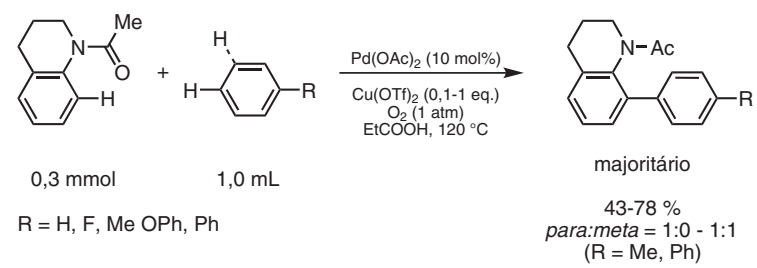

$$
\mathrm{R}^{5}=\text { alquila, arila, } \mathrm{CO}_{2} \mathrm{Me}
$$

Esquema 7. Cicloaromatização de alcinos com duas ativações de ligação C-H para a preparação de naftalenos

monossubstituído já possui cinco ligações $\mathrm{C}-\mathrm{H}$, que podem não ser iguais entre si, isto é, levarão a produtos diferentes. Além disso, cada uma destas ligações está sujeita a um ambiente estérico e eletrônico distinto. Neste sentido, o estudo do mecanismo de reação é uma das principais ferramentas que podem indicar onde estão as sutis diferenças que levarão ao melhor controle da seletividade.

\section{Evolução: do mecanismo da arilação direta aos aspectos gerais da ativação C-H}

O ciclo catalítico das transformações envolvendo ativações de ligação C-H é muito similar aos aceitos para os acoplamentos cruzados. Para as reações com um dos anéis aromáticos pré-funcionalizado, ocorre a adição oxidativa do metal que, em seguida, realiza a ativação da ligação C-H de forma inter- ou intramolecular. Com os dois grupos arilas na esfera de coordenação do metal, ocorre a etapa de eliminação redutiva (Figura 1A). Em alguns casos, quando a ativação da ligação C-H é direcionada por um ligante, ela pode ocorrer antes da introdução do grupo aromático pré-funcionalizado na esfera de coordenação do metal (Figura 1B). Este tipo de ativação "intramolecular" é tido como um processo mais fácil de ocorrer ${ }^{1}$ e é denominado na literatura como "ciclometalação" ou "funcionalização C-H dirigida por ligante". ${ }^{28}$

Para o acoplamento de grupos aromáticos não pré-funcionalizados, o ciclo catalítico, em linhas gerais, é o mesmo descrito acima. Contudo, é imprescindível o intercâmbio entre os grupos aromáticos ao se introduzirem na esfera de coordenação do metal, para que não ocorra homoacoplamento, já que normalmente um deles está em excesso (Figura 2). Esta é uma das razões pelas quais a esmagadora maioria dos trabalhos faz uso de compostos aromáticos com ca- 
A)

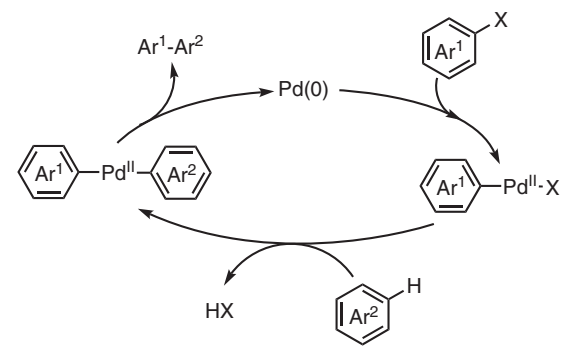

B)

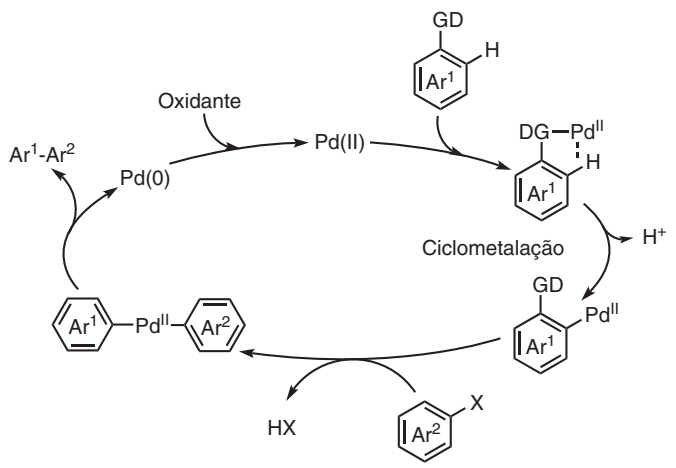

Figura 1. Ciclo catalítico geral para a formação de biarilas com um dos anéis pré-funcionalizados

racterísticas distintas, tais como um heteroaromático (indol, pirrol, benzofurano, etc) e um areno simples (benzeno, anisol, xilenos, etc). As pequenas diferenças eletrônicas (acidez, comprimento de ligação, por exemplo) e estéreas (impedimento estérico, ligantes diretores, por exemplo) respondem, em boa medida, por esta requerida inversão de seletividade. Estas características do mecanismo delineiam as limitações desta metodologia.

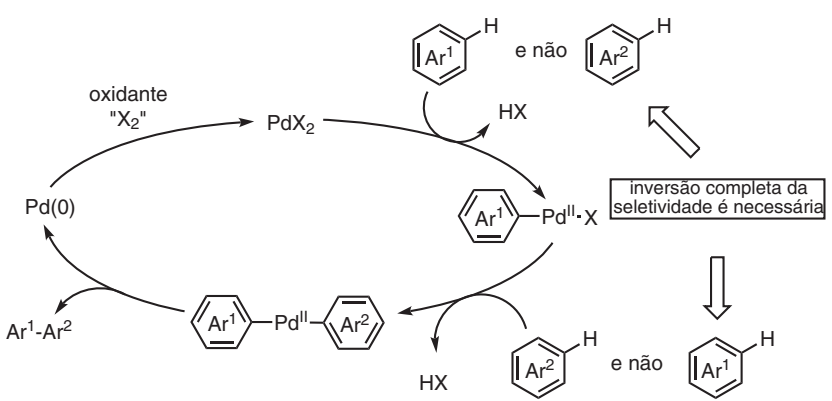

Figura 2. Ideia de inversão na seletividade de Fagnou. Adaptada da ref. 18

Além destas observações sobre o ciclo catalítico, diversos autores ocuparam-se em esclarecer o exato mecanismo de clivagem da ligação C-H e formação do complexo $\sigma$-organil, principalmente nas reações mediadas por paládio. É consenso de que o mecanismo operante depende do meio reacional e dos ligantes que circundam o metal em cada caso, ${ }^{12}$ mas o caminho metalação-desprotonação concertada (concerted metalation-deprotonation, CMD) parece ser um fenômeno geral (Esquema 8), mesmo nos processos cuja ocorrência de ciclometalação é adotada como estratégia. ${ }^{29}$

A ideia central deste mecanismo é que, de forma concertada, à medida que a ligação metal-carbono é formada, uma base, normalmente carboxilatos ou carbonatos (como ilustrado no Esquema 8), retire o hidrogênio ligado ao carbono. ${ }^{30}$ Desta forma, como não há adição oxidativa do metal à ligação $\mathrm{C}-\mathrm{H}$, o estado de oxidação do centro metálico não varia. Por isso, também, se faz necessário um oxidante no meio, pois após a eliminação redutiva que forma o composto

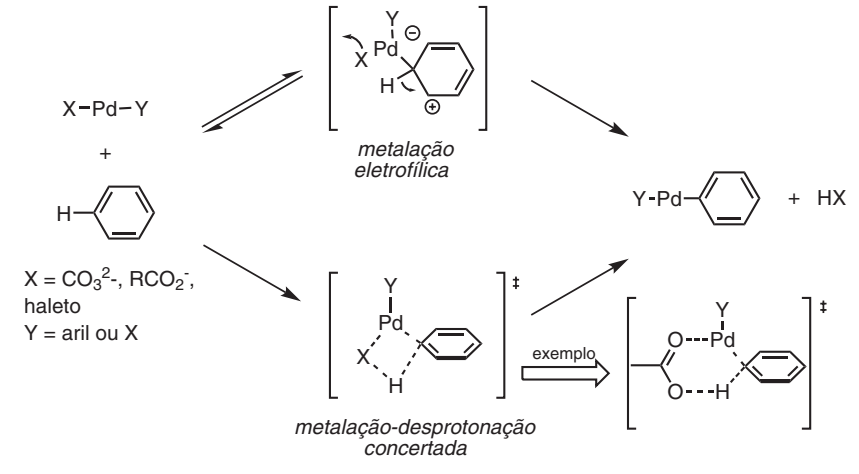

Esquema 8. Representação dos mecanismos de metalação eletrofílica e metalação-desprotonação concertada (CMD)

biarílico, paládio zero é formado e para voltar ao início do ciclo (e realizar outra CMD), ele deve antes voltar ao estado de oxidação +2 .

Este mecanismo foi proposto por Fagnou ${ }^{31}$ para tentar compreender aspectos de regiosseletividade e a não obediência aos critérios de orientação observados na substituição aromática eletrofílica ou na ordem de acidez, que seriam evidentes no caso do mecanismo se passar por uma desprotonação (reação ácido-base). Outra evidência deste mecanismo é o aumento da eficiência reacional na presença de quantidades subestequiométricas de carboxilatos (pivalatos, acetatos, ácidos orgânicos, etc). ${ }^{17,18}$

DeBoef e colaboradores ${ }^{32}$ consideraram este mecanismo apenas outra forma de nomear a metátese de ligação $\sigma$, também racionalizado e demonstrado por Hull e Sanford. ${ }^{33}$ Outros grupos de pesquisa, embora ainda trabalhem com a hipótese de substituição aromática eletrofílica, admitem também que o mecanismo CMD pode ocorrer. ${ }^{34}$ Arockiam e colaboradores ${ }^{16}$ sugeriram que a mesma maneira de clivar ligações C-H ocorre com complexos de rutênio (II). Ou seja, é possível que este mecanismo venha a ser estendido a outros metais. ${ }^{35}$

Contudo, é importante ressaltar que embora este mecanismo tenha sido bem aceito na literatura, ainda existem questões em aberto, como, por exemplo, qual a espécie de paládio que está envolvida em cada caso, i.e., quais são os ligantes presentes no meio que estão coordenados ao paládio. Um exemplo de como ainda existem aspectos a serem elucidados diz respeito à participação dos ligantes do tipo fosfina nas ativações C-H mediadas por paládio. Estes ligantes são considerados essenciais para a manutenção dos complexos de paládio em solução, o que implica na sua assistência ao longo de todo o ciclo catalítico em inúmeras reações. No entanto, de forma geral, estes ligantes possuem uma demanda estérica significativa e foram relatadas recentemente evidências de que não estão ligados ao paládio no momento da clivagem da ligação $\mathrm{C}-\mathrm{H} \cdot{ }^{36}$

A despeito da discussão sobre o mecanismo, introduzida e detalhada com aspectos de arilação direta, é importante considerar também outras observações, que já foram descritas na literatura e merecem citação, pois auxiliam no entendimento/análise dos métodos empregados. Para o processo como um todo, é importante a divisão proposta de que existem dois modos de ativação C-H com complexos metálicos, diferenciados pela maneira como os metais atuam na ligação $\mathrm{C}-\mathrm{H}$.

O primeiro modo de ativação compreende os mecanismos que levam à formação de um complexo metálico $\sigma$-organil. Este é o que mais guarda semelhança com a química tradicional de acoplamento cruzado, reações de substituição e adição mediadas por metais de transição, pois de certa forma a ligação $\mathrm{C}-\mathrm{H}$ é pensada como uma ligação $\mathrm{C}-\mathrm{X}$ ( $\mathrm{X}=$ halogênio, triflato, boro, estanho, etc). As arilações diretas, por exemplo, encaixam-se neste modo, assim como os exemplos da próxima seção. 
Este modo de ativação pode ser dividido, basicamente, em quatro mecanismos (Figura 3). ${ }^{37}$ Destes, a adição oxidativa e a substituição eletrofílica são os mais utilizados para interpretar os resultados de ativação $\mathrm{C}-\mathrm{H}$, com vantagem para a segunda rota. Com a elaboração da alternativa metalação-desprotonação concertada, a metátese de ligação $\sigma$ adquiriu sua importância também.

$$
\begin{aligned}
& \text { adição oxidativa }
\end{aligned}
$$

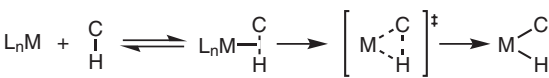

metátese de ligação $\sigma$

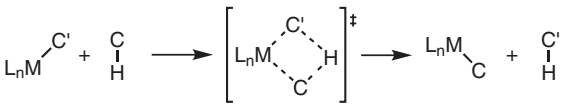

substituição eletrofílica

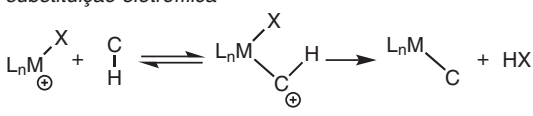

adição 1,2

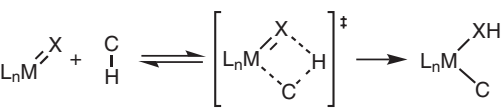

Figura 3. Representações esquemáticas dos diferentes mecanismos de ativação $C$-H propostos para a formação de um complexo metálico $\sigma$-organil

Já o segundo modo inclui a quebra da ligação C-H sem a formação de uma ligação M-C, levando, em geral, à formação de radicais. Este modo é dividido em dois casos: no primeiro, o complexo metálico tem a função de abstrair um átomo de hidrogênio ou um elétron do hidrocarboneto, gerando um radical capaz de reagir com outras espécies do meio (Figura 4); no segundo, ocorre a ativação pelo complexo metálico de um terceiro reagente (por ex., $\mathrm{O}_{2}$ ) que leva à formação de uma espécie capaz de atacar o hidrocarboneto. ${ }^{1}$ Frequentemente, as reações que ocorrem por este modo de ativação são nomeadas de "oxidação de ligações C-H" ou "inserção em ligações C-H", sendo inclusive não consideradas por alguns como uma "ativação C-H". No entanto, como ao final do processo ocorre a funcionalização da ligação $\mathrm{C}-\mathrm{H}$, alguns exemplos pertinentes foram considerados na última parte deste texto.

\section{A) Oxidação C-H:}

$$
\mathrm{RH}+\mathrm{O}=\mathrm{M}^{\mathrm{n}+} \longrightarrow \mathrm{R} \cdot+\mathrm{HO}-\mathrm{M}^{(\mathrm{n}-1)+} \longrightarrow \mathrm{ROH}+\mathrm{M}^{(\mathrm{n}-2)+}
$$

B) Inserção C-H (exemplificada para inserção de carbenos)

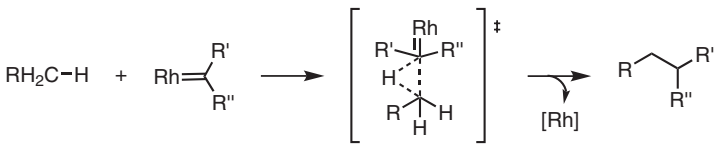

C) Ativação de um terceiro reagente pelo metal

$$
\mathrm{M}^{\mathrm{n}+}+\mathrm{X} \longrightarrow \mathrm{M}^{(\mathrm{n}-1)+}+\mathrm{X} \cdot \stackrel{\mathrm{RH}}{\longrightarrow} \mathrm{R} \cdot+\mathrm{HX} \underset{-1 \mathrm{e}^{-}}{\stackrel{\mathrm{Y}}{\longrightarrow}} \mathrm{RY}
$$

Figura 4. Representações esquemáticas do segundo modo de ativação $C-H$

Todavia, independente do modo de ativação, dentre os diversos metais disponíveis para executar uma ativação C-H, o paládio é, por excelência, o principal metal utilizado. ${ }^{28}$ No entanto, outros metais são também empregados, e.g., ródio ${ }^{38}$ e rutênio, ${ }^{39}$ atuando muitas vezes de forma precisa cirúrgica, realizando com maestria o que paládio não faz, ou não faz muito bem em determinadas condições. Do ponto de vista sintético, embora o paládio esteja sempre na vanguarda, os três metais de transição são ferramentas valiosíssimas. O uso de outros metais, tais como ferro, rênio, irídio, cobre, ${ }^{14,40}$ platina, ósmio e níquel, é também relatado na literatura, mas em menor extensão. ${ }^{41}$

Obviamente, como todas as metodologias, as ativações $\mathrm{C}-\mathrm{H}$ também apresentam vantagens e desvantagens. O primeiro aspecto vantajoso da ativação de ligações $\mathrm{C}$-H é a dispensa de reagentes préfuncionalizados. ${ }^{42}$ No caso das reações de arilação direta, dispensa-se o uso de anéis aromáticos pré-ativados com haletos, triflatos, grupos com boro ou estanho ou outros metais substituídos in situ, como lítio e magnésio, por exemplo. ${ }^{12}$ Ao realizar uma arilação direta com dois arenos não ativados, ao invés de se gerar como resíduo quantidades estequiométricas do agente de ativação (i.e., boro, estanho, haletos, etc), produz-se como resíduo um aduto base-hidrogênio. Mesmo que a arilação direta utilize apenas um dos arenos pré-funcionalizado, ainda assim a quantidade de resíduos gerada será menor em comparação com as metodologias tradicionais.

Contudo, basta um olhar mais atento às condições experimentais e as desvantagens das arilações diretas aparecem: normalmente é necessário um agente oxidante em quantidade estequiométrica. Se este oxidante for um metal, tal como um sal de prata ou cobre, a geração de quantidades estequiométricas de resíduo metálico permanecerá. Para os oxidantes orgânicos, valem os mesmos argumentos. Além disso, temperaturas superiores a $100{ }^{\circ} \mathrm{C}$ são frequentes, assim como os longos tempos reacionais e o baixo número de ciclos catalíticos (turnover number, TON), o que requer uma carga maior de catalisador e/ou ligantes, que normalmente não são baratos.

No cômputo geral, no entanto, as arilações diretas acabam por ter a vantagem de não necessitarem da pré-ativação de, pelo menos, um dos reagentes. Por exemplo, a preparação de haletos aromáticos com um padrão de substituição definido, a partir dos substratos extraídos das reservas naturais de petróleo e gás natural, requer diversas etapas de reação e/ou de purificação, que fazem deste processo alvo de muito esforço, onerando o processo econômica e ambientalmente.

No final das contas, a justificativa para levar parte do esforço da pesquisa às ativações de ligação $\mathrm{C}-\mathrm{H}$ reside nos enormes ganhos futuros que o domínio desta tecnologia pode trazer. Há pleno reconhecimento que as condições ainda drásticas, a não tolerância a diversos grupos funcionais devido à temperatura, condições oxidantes e outras variáveis do meio, assim como a encruzilhada da seletividade, são problemas de resolução complexa, mas como para outras tecnologias, não há dúvidas de que avanços são possíveis.

\section{MISSÃO CUMPRIDA (E COMPRIDA): A ATIVAÇÃO C-H É UMA REALIDADE}

As arilações diretas mostraram que a ativação $\mathrm{C}-\mathrm{H}$ é um processo possível de se realizar, com eficiência e seletividade. Contudo, mais que a clivagem de ligações $\mathrm{C}\left(\mathrm{sp}^{2}\right)-\mathrm{H},{ }^{43}$ a funcionalização de ligações $\mathrm{C}\left(\mathrm{sp}^{3}\right)$-H é um desafio ainda maior, pois estes hidrogênios são menos ácidos e as ligações possuem energias de dissociação mais altas. Outro complicador é o perfil energético dos orbitais da ligação $\mathrm{C}\left(\mathrm{sp}^{3}\right)-\mathrm{H}$, pouco suscetível à interação com o centro metálico. Assim sendo, algum artifício deve ser usado para direcionar a ativação da ligação $\mathrm{C}\left(\mathrm{sp}^{3}\right)-\mathrm{H}$. Os dois exemplos seguintes são relativamente simples, mas já dão uma boa ideia do seu potencial, pois utilizam estratégias diferentes para tornar eficiente e regiosseletiva a ativação $\mathrm{C}-\mathrm{H} .{ }^{44}$

Em 2008, Shibata e colaboradores ${ }^{45}$ relataram a preparação de alil amidas através da alquenilação de metil amidas, catalisada por um complexo catiônico de irídio, na presença de ( \pm )-BINAP como ligante. Os tempos reacionais ficaram entre 6 e $72 \mathrm{~h}$, à temperatura de $135{ }^{\circ} \mathrm{C}$, com os rendimentos variando entre 29 e $82 \%$ (Esquema 9). Os autores argumentaram, após experimentos com a $N, N$-dimetil benzilamina (i.e., sem a carbonila para a complexação) e a $N$-metil$d^{3}$-pirrolidona, que a etapa-chave era a formação do intermediário 
cíclico com ligação C-Ir formada através de uma ativação C-H em carbono $\mathrm{sp}^{3}$.

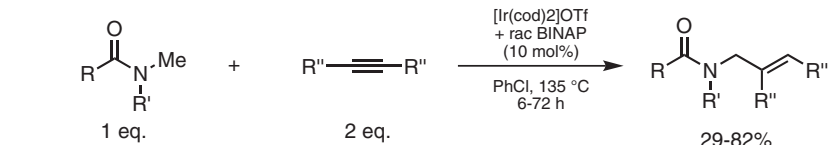

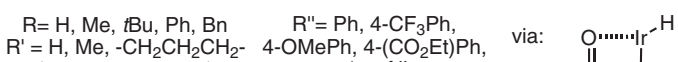

$$
\begin{aligned}
& \text { (N-metilpirrolidona) 1-naftil }
\end{aligned}
$$

Esquema 9. Preparação de alil amidas via ativação $C\left(s p^{3}\right)-H$ catalisada por irídio

Apesar de estruturalmente simples, este trabalho demonstra um raro exemplo de ativação seletiva de uma ligação $\mathrm{C}\left(\mathrm{sp}^{3}\right)-\mathrm{H}$ na presença de ligações $\mathrm{C}-\mathrm{H}$ aromáticas (quando $\mathrm{R}=\mathrm{Ph}$ ). Provavelmente, esta seletividade decorreu da coordenação inicial do metal com a carbonila, que dirigiu a clivagem da ligação C-H levando à formação do anel de cinco membros. A hiperconjugação com o nitrogênio pode ter ajudado na seletividade, pela estabilização da carga positiva (Hull e Sanford ${ }^{33}$ obtiveram um $\rho<0$ para a constante de Hammett) que é gerada na quebra da ligação $\mathrm{C}-\mathrm{H}$. Diferentemente, a carga positiva que seria parcialmente gerada na ativação da ligação C-H aromática estaria no orbital $\mathrm{sp}^{2}$, o que impediria sua estabilização por outros efeitos que não o indutivo.

Um complexo de irídio também foi utilizado pelo grupo de Murahashi, ${ }^{46}$ para realizar o acoplamento entre compostos trifluorometilados e acrilonitrila ou metil vinil cetona (Esquema 10). Os tempos de reação variaram bastante $(1-40 \mathrm{~h})$ e algumas reações precisaram ser aquecidas a $110{ }^{\circ} \mathrm{C}$ para se concretizarem. Quando dois hidrogênios vizinhos ao grupo trifluorometila estavam presentes, ambos foram substituídos. A mesma reação foi catalisada por $\left[\mathrm{Ru}(\mathrm{Cp} *) \mathrm{H}\left(\mathrm{PPh}_{3}\right)_{2}\right]$ em rendimentos comparáveis. Experimentos de controle na presença de diversas bases não levaram à formação do produto ou à sua formação em rendimento não superior a $27 \%$ (evidência para a não ocorrência de adição do tipo Michael por um nucleófilo).

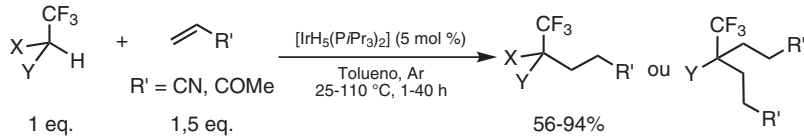

$$
\begin{aligned}
& \text { para } X=\mathrm{H} \\
& \mathrm{X}=\mathrm{CF}_{3}, \mathrm{Y}=\mathrm{CO}_{2} \mathrm{Me}, \mathrm{CF}_{2} \mathrm{OMe} \\
& \mathrm{X}=\mathrm{F}, \mathrm{Y}=\mathrm{CN} \\
& \mathrm{X}=\mathrm{Y}=\mathrm{CO}_{2} \mathrm{Me} \\
& \mathrm{X}=\mathrm{H}, \mathrm{Y}=\mathrm{CN}, \mathrm{CO}_{2} \mathrm{Me}
\end{aligned}
$$

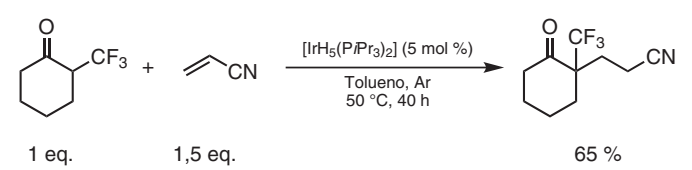

Esquema 10. Alquilação de compostos trifluorometilados via ativação $C\left(s p^{3}\right)$ H catalisada por irídio

O mecanismo proposto pelos autores inicia-se pela ativação da ligação $\mathrm{C}-\mathrm{H} \alpha$ ao grupo trifluorometila, seguido da inserção do alqueno e eliminação redutiva para formar o produto. Diferentemente do exemplo anterior, o substrato em questão não possui um heteroátomo para dirigir o metal à ligação C-H que deve ser quebrada, há apenas uma diferença eletrônica acentuada, em virtude do grupo trifluorometila, que deve direcionar a ativação $\mathrm{C}-\mathrm{H}$. O resultado obtido com a $\alpha$-trifluorometil cicloexanona foi uma evidência desta hipótese (Esquema 10).

Liégault e Fagnou, ${ }^{47}$ deram um passo adiante na complexidade reacional e descreveram a ativação em cascata de uma ligação $\mathrm{C}\left(\mathrm{sp}^{2}\right)$ $\mathrm{H}$ e outra $\mathrm{C}\left(\mathrm{sp}^{3}\right)-\mathrm{H}$ na formação de sistemas bicíclicos (Esquema 11). Uma base, mesmo em quantidade subestequiométrica foi imprescindível para se obter bons rendimentos e foi observada uma boa seletividade para o grupo metila na ativação $\mathrm{C}\left(\mathrm{sp}^{3}\right)-\mathrm{H}$, na presença de outros grupos alquila. O efeito cinético-isotópico relatado de 5,1 para o hidrogênio no grupo metila evidencia que a etapa determinante envolve a quebra da ligação $\mathrm{C}\left(\mathrm{sp}^{3}\right)-\mathrm{H}$. O fato de não usar halogênios ou grupos diretores, assim como o emprego de ar atmosférico como oxidante, tornam este trabalho um ótimo exemplo do nível de economia atômica e diminuição da geração de resíduos a que pode chegar um processo sintético com este tipo de estratégia (i.e., ativação C-H).

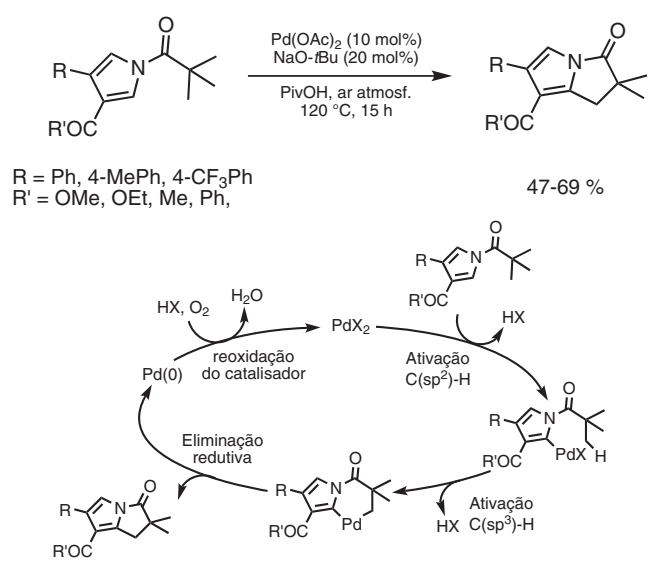

Esquema 11. Ativações de ligações $C\left(s p^{2}\right)-H$ e $C\left(s p^{3}\right)$-H em cascata para formação de sistemas bicíclicos

A maioria das ativações $\mathrm{C}\left(\mathrm{sp}^{3}\right)$-H precisam de um grupo diretor. ${ }^{44}$ No primeiro exemplo citado (Esquema 9), o grupo diretor foi a carbonila da amida, mas em outros casos, uma ligação $\pi \mathrm{C}$-C pode também realizar esta função. A ativação de ligações $\mathrm{C}-\mathrm{H}$ alílicas é um dos exemplos mais recorrentes na literatura. ${ }^{48} \mathrm{O}$ grupo de M. C. White é um dos que mais se destaca na formação de ligações C-heteroátomo através de ativações $\mathrm{C}-\mathrm{H}$. Esta abordagem reduz significativamente o número de etapas para a obtenção de blocos sintéticos substituídos com oxigênio e/ou nitrogênio.

Aproveitando-se da habilidade do complexo de Pd(II)/bis-sulfóxido em formar um intermediário $\pi$-alil paládio mediante ativação $\mathrm{C}-\mathrm{H}$ alílica, White e colaboradores descreveram a preparação de diversas alil amidas ${ }^{49}$ (Esquema $12 \mathrm{~A}$ ) e 1,3-aminoálcoois alílicos (Esquema $12 \mathrm{C}),{ }^{50}$ pelo ataque de $\mathrm{N}$-tosilcarbamatos a estes intermediários (Esquema 12). Alguns substratos possuindo centros estereogênicos ( $\mathrm{R}^{*}$ ) foram testados sem que estes centros fossem afetados. Os autores ainda demonstraram a aplicação de sua metodologia na aminação de um derivado do cedreno (Esquema 12 C) e na síntese enantiosseletiva da (+)-allosedridina (Esquema $12 \mathrm{D})$, ambos com bons rendimentos e seletividades.

Uma das metodologias mais elegantes elaborada pelo grupo de White foi a macrolactonização via um intermediário $\pi$-alil paládio, seguido do ataque de uma carboxila. ${ }^{51}$ Recentemente, a viabilidade de aplicação desta reação, baseada na ativação de ligação C-H alílica, foi demonstrada na síntese do produto natural 6-desoxieritronolídeo $\mathrm{B},{ }^{52}$ um precursor dos antibióticos do tipo eritromicina, a partir de um intermediário avançado, obtido após 18 etapas (Esquema 13).

$\mathrm{O}$ fato da oxidação C-H alílica ocorrer nas últimas etapas da síntese é significativo, pois permite que os mesmos sejam acionados 


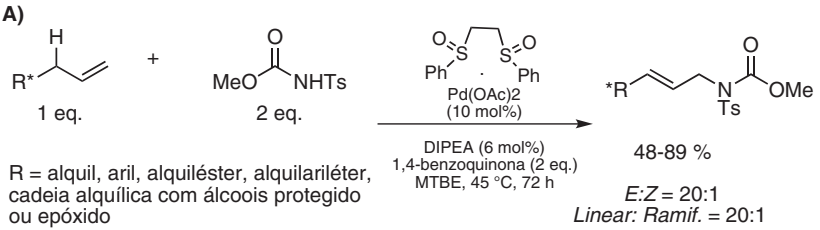

B)

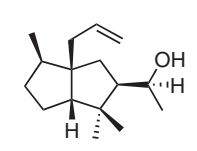

Derivado do cedreno

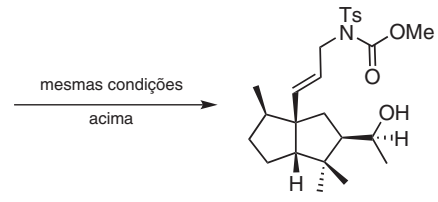

Rend.: $80 \%$

$E: Z=20: 1$

c)

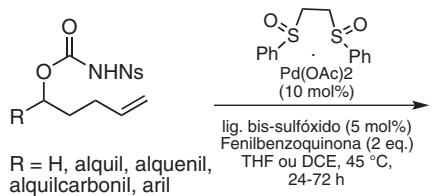

D)

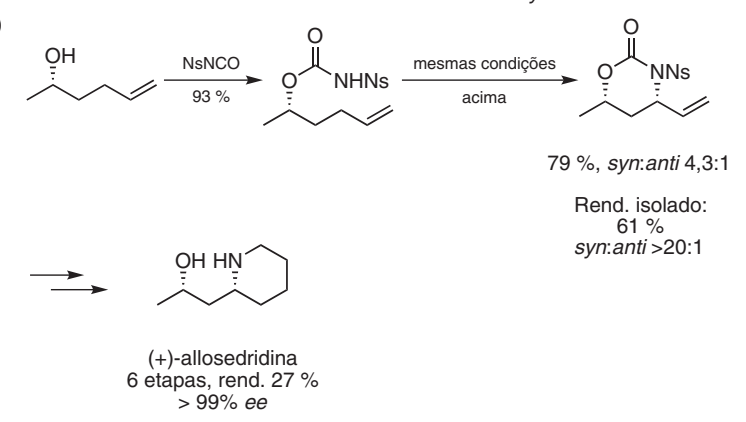

Esquema 12. Ativação de ligações $C$-H alílicas na preparação de alil amidas e 1,3-aminoalcoóis alílicos: aplicações nas sínteses da alil amida derivada do cedreno e na síntese assimétrica da (+)-allosedridina

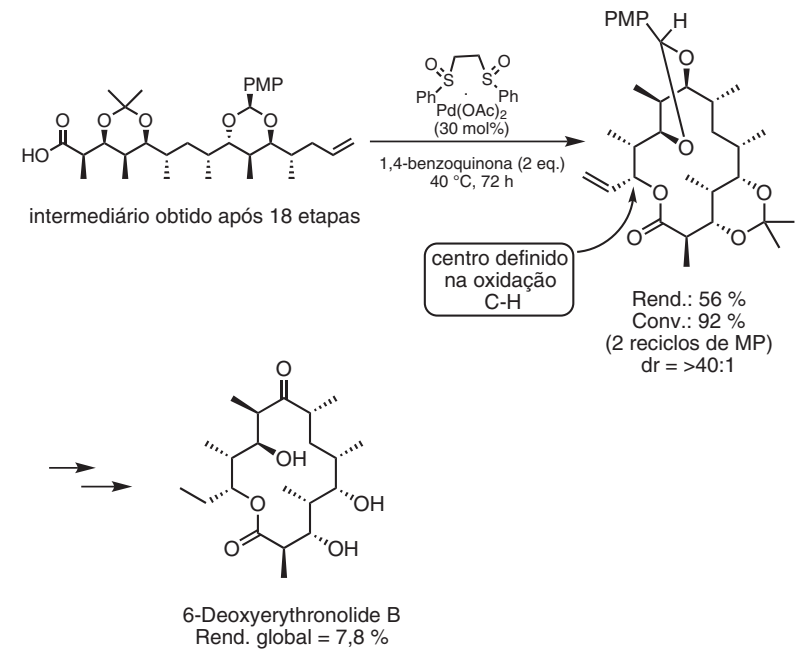

Esquema 13. Síntese do produto natural 6-desoxieritronolídeo B via oxidação de ligação $\mathrm{C}$-H alílica somente quando conveniente à rota sintética. A conversão do grupo $\mathrm{C}-\mathrm{H}$ em grupos funcionais mais reativos muito cedo na rota sintética poderia causar reações paralelas ao longo da síntese e precisaria ser protegido para não diminuir a eficiência global do processo. Ou seja, é como se ligação C-H funcionasse como um grupo de proteção, que permitisse a instalação de um grupo funcional em estágios avançados da síntese, sem prejuízo para a pureza óptica do produto final e sem sofrer interferência dos diversos grupos funcionais presentes.

Dados os desenvolvimentos na ativação de ligações $\mathrm{C}\left(\mathrm{sp}^{3}\right)-\mathrm{H}$, exemplificados na complexidade estrutural por este último trabalho de White e colaboradores, o problema da estereosseletividade surgiu naturalmente. Diversos trabalhos visando à obtenção diastereo- e/ou enantiosseletiva de adutos já foram descritos na literatura. ${ }^{53}$ Tran e Cramer ${ }^{54}$ por exemplo, relataram a alilação $s y n$-seletiva de iminas aromáticas catalisada por ródio (I). Além da proposição para a diastereosseletividade observada, os autores relataram uma variante enantiosseletiva desta reação, que forneceu o produto com $68 \%$ de excesso enantiomérico (ee) (Esquema 14).
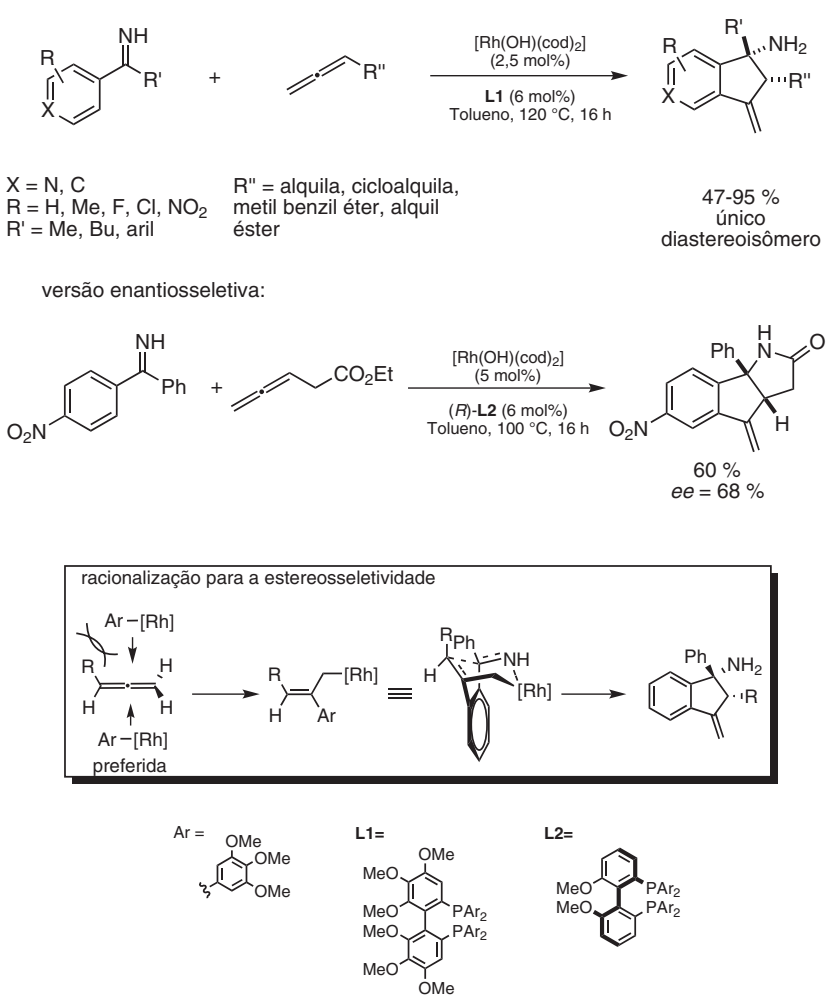

Esquema 14. Alilação syn-diastereosseletiva de iminas catalisada por ródio via ativação de ligação $C\left(s p^{2}\right)-H$

A dificuldade maior de elaborar protocolos estereosseletivos, em especial os enantiosseletivos, com ativações $\mathrm{C}-\mathrm{H}$ são as condições reacionais drásticas, envolvendo longos tempos reacionais e aquecimento vigoroso. Tais condições tendem a dificultar o reconhecimento estéreo. Mesmo diante dessas dificuldades, alguns resultados importantes têm sido descritos. ${ }^{55,56} \mathrm{O}$ trabalho de Yu e colaboradores,${ }^{57}$ por exemplo, consistiu na diferenciação de ligações $\mathrm{C}-\mathrm{H}$ enantiotópicas de anéis aromáticos através do uso de aminoácidos $N$-protegidos com grupos volumosos como ligantes na alquilação destes anéis (Esquema 15 A), sendo obtidos excessos enantioméricos de razoáveis a bons (54-95\% ee).

Depois desta prova de conceito, os autores tentaram estender a metodologia para a ativação de ligações $\mathrm{C}\left(\mathrm{sp}^{3}\right)$-H enantiotópicas, mas os mesmos níveis de rendimento e seletividade não foram alcançados (Esquema $15 \mathrm{~B}$ ). Este resultado demonstra uma diferença significativa 
A)<smiles>c1ccc(C(c2ccccc2)c2ccccn2)cc1</smiles>

$\mathrm{R}^{\prime}=\mathrm{H}, \mathrm{Me}, \mathrm{OMe}, \mathrm{OAc}$

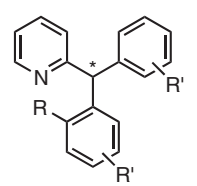

$43-96 \%$
$0.95 \%$

L1 R $=0-(-)-$ menti L2 R = OtBu

B)

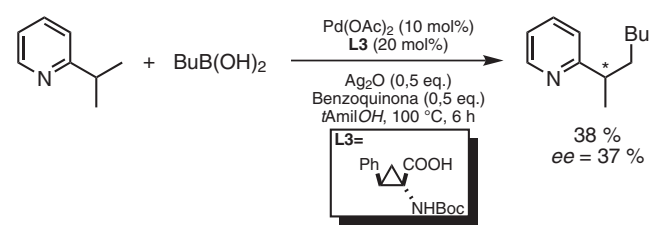

C)
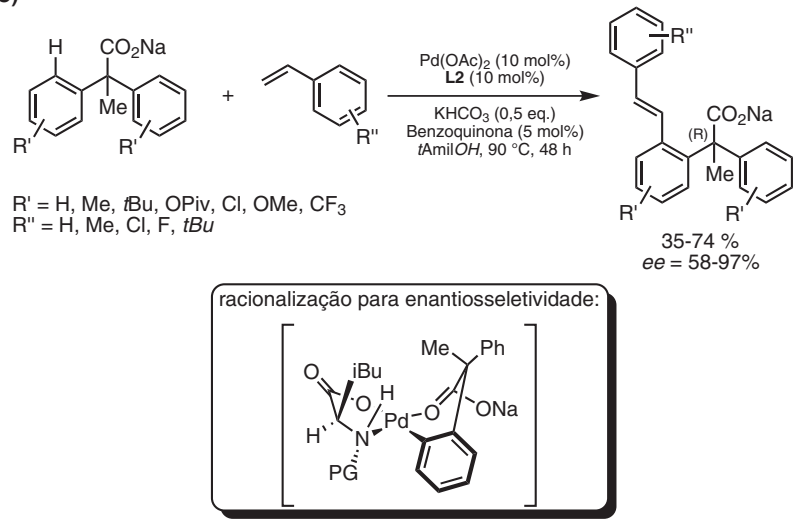

Esquema 15. Alquilação/alquenilação seletiva de grupos enantiotópicos catalisada por paládio usando aminoácidos como ligantes

na facilidade de se fazer ativação C-H estereosseletiva em carbonos $\mathrm{sp}^{2}$ ou $\mathrm{sp}^{3}$. Ainda, em 2010, os mesmos pesquisadores ${ }^{58}$ relataram a olefinação enantiosseletiva de anéis aromáticos, usando como substratos sais de ácidos diaril acéticos. Novamente, as seletividades voltaram a ficar entre boas e excelentes e bons rendimentos foram obtidos (Esquema $15 \mathrm{C}$ ), em condições semelhantes às do trabalho anterior. ${ }^{57}$

A racionalização para a enantiosseletividade obtida nestas três reações de Yu e colaboradores segue o mesmo modelo geral, exemplificado no Esquema 15 para a equação C. A primeira parte consiste na complexação de um grupo diretor (nitrogênio piridínico ou carbonila do grupo carboxila) ao metal e na amarração deste intermediário com o ligante aminoácido, através da complexação de sua carboxila e seu nitrogênio protegido. A ativação $\mathrm{C}-\mathrm{H}$ acontece quando o grupo mais volumoso (i.e., fenil) do carbono central do substrato está para o lado oposto ao da cadeia lateral do aminoácido, ou seja, forma-se o intermediário favorecido por razões estéreas. Neste ponto, o substrato $\mathrm{C}_{2}$-simétrico converte-se em um complexo metálico $\sigma$-organil quiral, não racêmico. Observe-se que o grupo volumoso que protege o nitrogênio desfavorece o deslocamento do carbono central do substrato para "baixo" (do plano de coordenação dos quatro ligantes do paládio, relativo ao desenho no Esquema 15), pois colocaria o grupo protetor e os substituintes deste carbono central muito próximos. $\mathrm{O}$ conjunto destes fatores contribui para a rigidez do estado de transição e, portanto, para a enantiosseleção.

\section{FRONTEIRA: O CONSTANTE DESAFIO DO PASSO À FRENTE}

A partir dos exemplos mostrados anteriormente, é possível visualizar claramente que nem todas as dificuldades foram resolvidas até

o momento. No entanto, condições reacionais mais amenas e rendimentos melhores são relatados quase que diariamente na literatura. Muitos autores têm envidado esforços para a questão da seletividade,${ }^{53}$ enquanto outros têm continuado na busca de catalisadores e/ou ligantes mais robustos. ${ }^{59}$

Um bom exemplo de como o avanço em todas estas questões não é trivial, é a reação de Fujiwara-Moritani intermolecular enantiosseletiva, relatada em 1999, por Mikami e colaboradores (Esquema 16). ${ }^{60}$ Neste trabalho, uma nitrila cíclica $\alpha, \beta$-insaturada foi arilada usando o benzeno como agente arilante, na presença de acetato de paládio e um ligante quiral, além de um peróxido orgânico como oxidante. Após $9 \mathrm{~h}$ de aquecimento a $100{ }^{\circ} \mathrm{C}$, o produto desejado foi obtido em apenas $19 \%$ de rendimento e $49 \%$ de $e e$. Esta reação é análoga à reação de Heck-Mizoroki,${ }^{61}$ com a diferença de que ao invés da inserção do paládio em uma ligação C-X ( $\mathrm{X}=\mathrm{OTf}$, halogênio, etc), o que precede a formação do intermediário $\sigma$-arilpaládio é uma ativação $\mathrm{C}\left(\mathrm{sp}^{2}\right)-\mathrm{H}$.
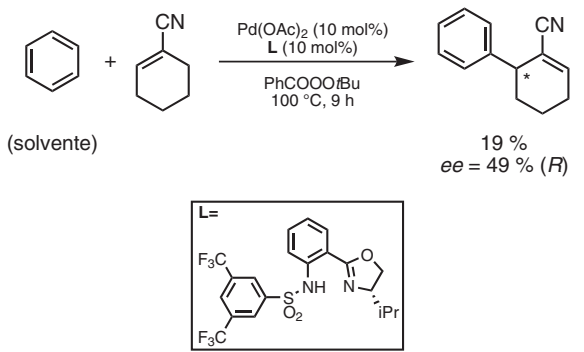

Esquema 16. Versão enantiosseletiva da reação de Fujiwara-Moritani

Se para a reação de Heck-Mizoroki existem diversos protocolos enantiosseletivos descritos, ${ }^{62}$ para a reação de Fujiwara-Moritani, um dos poucos relatos, se não único, foi feito por Mikami e colaboradores. $\mathrm{O}$ trabalho de Yu e colaboradore $\mathrm{s}^{58}$ comentado anteriormente (Esquema 15) tem algumas semelhanças, mas não é exatamente a mesma estratégia. A ativação $\mathrm{C}-\mathrm{H}$ pode ser um complicador mais significativo do que se pensa atualmente e isto aumenta a perspectiva de que este campo de pesquisa fique em voga por muito tempo.

Frequentemente, a solução de diversos problemas de reatividade e seletividade na catálise por metais de transição traz a reboque novos ligantes, capazes de estabilizar intermediários de um ciclo catalítico e/ou favorecer a formação discriminada de estados de transição que levem a produtos isoméricos. Dentre os metais utilizados, o ródio é bastante acionado nas versões diastereo- e/ou enantiosseletivas, dado que é compatível e maleável a presença de ligantes que possam ajudar na estereosseleção. ${ }^{53}$

A inserção de carbenos metálicos, em especial de ródio, faz parte do segundo modo de ativação $\mathrm{C}$-H, no qual não ocorre a formação de um complexo $\sigma$-organil. Embora conceitualmente diferente das estratégias até agora apresentadas, e também um pouco mais antiga, esta química mostrou-se muito útil para a ativação C-H estereosseletiva, exibindo alto desempenho catalítico (i.e., alto TON) e ótima estereosseletividade em diversos casos. ${ }^{53,63}$

A maneira mais tradicional de gerar carbenos é a extrusão de nitrogênio induzida pelo ródio em compostos diazocarbonílicos. Estas espécies se caracterizam pelo comportamento eletrofílico acentuado e trazem consigo duas facetas que não podem ser desconsideradas: a ativação $\mathrm{C}-\mathrm{H}$ é sensível a fatores estéricos e eletrônicos e podem atuar sobre ligações $\mathrm{C}\left(\mathrm{sp}^{3}\right)$-H sem grandes dificuldades; além disso, esta química é bastante suscetível ao ambiente quiral dos ligantes complexados ao ródio e excessos enantioméricos bastante satisfatórios têm sido obtidos ao longo dos anos. O Esquema 17 aborda um exemplo bastante ilustrativo destas duas características. ${ }^{64}$ 


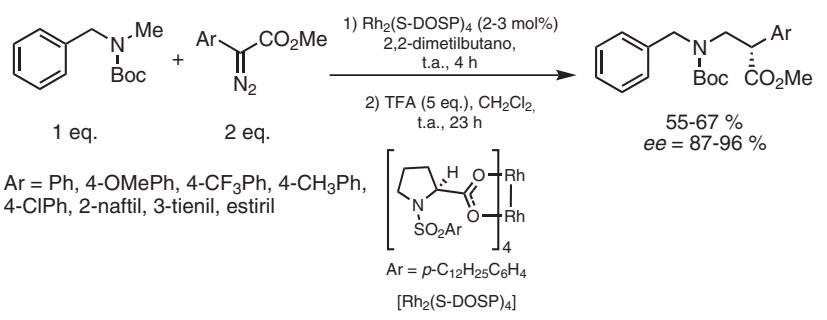

Esquema 17. Demonstração dos efeitos estéricos e eletrônicos na inserção de carbenos de ródio em ligações $\mathrm{C}$ - $\mathrm{H}$

As reações envolvendo carbenos, no entanto, encontram-se em outro patamar de desafio, que consiste na otimização da atividade catalítica aliada à reutilização do catalisador. Takeda e colaboradores ${ }^{65}$ descreveram recentemente a imobilização de um catalisador de ródio em um polímero do tipo poliestireno, resultando em um catalisador eficiente e durável, que manteve ao longo de uma centena de ciclos os mesmos bons níveis de rendimento e enantiosseletividade (Esquema 18). Os autores sugeriram que o compromisso atingido entre dispersão dos centros metálicos e intumescência do polímero foi essencial para os resultados obtidos.

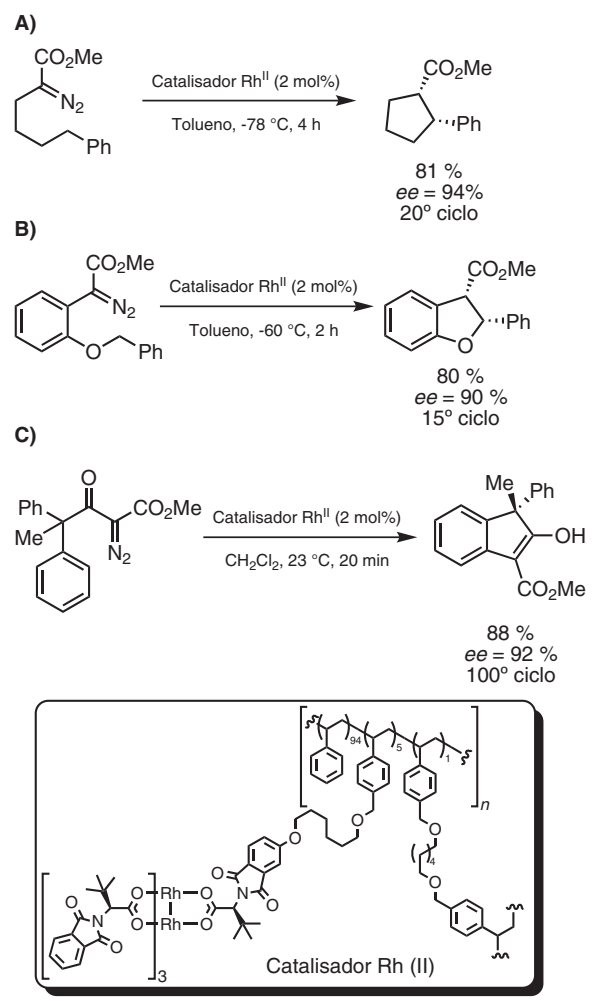

Esquema 18. Imobilização de um catalisador de ródio para otimização da atividade catalítica em reações de inserção $C$ - $H$ de carbenos

Considerando que a reatividade dos carbenos dificulta consideravelmente o trabalho experimental, ${ }^{66}$ sua aplicação em larga escala não é nada trivial, apesar de ser um método já descrito há algum tempo na literatura. Embora não exatamente recente, um exemplo como este merece menção neste texto, dado os avanços que proporciona (e deve continuar proporcionando) ao campo de ativação de ligações $\mathrm{C}-\mathrm{H}$.

A estratégia envolvendo carbenos tem aspectos distintos do mecanismo das abordagens comentadas anteriormente e algumas desvantagens. Há a necessidade de um composto diazo, com preferência aos compostos diazocarbonil, e a exacerbada reatividade destes carbenos pode causar problemas em estruturas mais complexas. Além disso, é comum o uso de ligantes do tipo fosfina e o uso de condições anidras de reação. Logo, apesar de uma boa alternativa, alguns pontos negativos sempre estão presentes. Por isso, a relação custo-benefício deve ser sempre muito bem avaliada.

O ideal seria que a ativação C-H pudesse ser feita na ausência de ligantes complexos e em ligações remotas, ou seja, sem o auxílio de grupos retiradores/doadores de elétrons e/ou grupos diretores, assim como na ausência de carbonos pré-ativados, presentes nos compostos diazo, por exemplo. No entanto, o mais complicado não é o desenvolvimento metodológico, mas a sua aplicação na síntese de moléculas orgânicas complexas, área na qual a ativação C-H tem adentrado paulatinamente. ${ }^{6}$

A idealidade nesta química é a modificação pontual, seletiva e sem danos para o restante da estrutura, que tenha reatividade e produtos previsíveis, assim como compatibilidade com estruturas complexas, dotadas de grupos funcionais, de preferência não protegidos. Se possível, regiosseletividade, diastereo- e enantiosseletividades devem ser obtidas com o uso mínimo de ligantes/catalisadores quirais. Alcançar todos estes critérios com qualidade usando como grupo funcional a ligação C-H consiste em um enorme desafio atual.

Neste sentido, os trabalhos conceitualmente mais avançados descritos na literatura foram relatados por Chen e White para a oxidação seletiva de $\mathrm{C}\left(\mathrm{sp}^{3}\right)$-H em cadeia alquílicas, na ausência de grupos diretores e com reatividade previsível. Eles descreveram uma condição reacional baseada em um complexo eletrofílico de ferro (II) e peróxido de hidrogênio, capaz de oxidar preferencialmente ligações carbono-hidrogênio terciárias a alcoóis e grupo metileno a carbonilas. A racionalidade apresentada na construção do modelo e sua verificação em moléculas mais complexas dão a esta estratégia um significado proeminente e aos trabalhos em si mérito incontestável.

Em 2007, Chen e White ${ }^{67}$ descreveram um protocolo experimental criterioso, que contou com a adição de três porções equivalentes de catalisador ( $\mathrm{Fe}(S, S-\mathrm{PDP}))$, ácido acético e peróxido de hidrogênio a cada $10 \mathrm{~min}$, perfazendo um total de $15 \mathrm{~mol} \%$ de catalisador, 1,5 eq. de ácido e 3,6 eq. de peróxido. As reações foram agitadas em acetonitrila à temperatura ambiente por $30 \mathrm{~min}$ (Esquema 19). Diversos substratos foram avaliados sob essa "condição padrão" e permitiu aos autores estabelecerem preferências de reatividade.

Em linhas gerais, estas preferências se baseiam na riqueza eletrônica da ligação C-H, na sua disponibilidade para aproximação do volumoso complexo de ferro (II) usado como catalisador e, eventualmente, na presença de um grupo diretor, que pode ser útil em alguns casos. No Esquema 19, é possível visualizar como cada fator interfere na regiosseletividade da oxidação C-H. É importante notar que para os substratos nos quais o carbono oxidado era um centro assimétrico, sua configuração foi mantida ao longo da reação (i.e., oxidação com retenção de configuração).

Para demonstrar a qualidade do modelo proposto, Chen e White submeteram três produtos naturais às condições padrão de oxidação. A (+)-artemisinina teve apenas a ligação C-H no carbono 10 oxidada, entre os cinco carbonos terciários presentes na molécula (Esquema $20 \mathrm{~A}$ ). Estes outros centros terciários se encontram em posição $\alpha$ ou $\beta$ ao grupo éster ou ao grupo endoperóxido, retiradores de elétrons e, portanto, desativadores. A mesma oxidação pode ser realizada por cultura microbiana de Cunninghamella echinulata em 4 dias, mas com rendimento inferior ao obtido na presença do catalisador $\mathrm{Fe}(S, S$-PDP).

Um exemplo de controle por fatores estéreos foi dado pela tentativa de oxidação da (-)- $\alpha$-di-hidropicrotoxinina (Esquema 20 B). Todas as ligações $\mathrm{C}-\mathrm{H}$ desta molécula são eletronicamente desativadas e a única ligação $\mathrm{C}-\mathrm{H}$ em carbono terciário encontra-se estericamente impedida; o material de partida foi recuperado em $92 \%$ ao submeterse esta molécula às condições padrão previamente estabelecidas. 

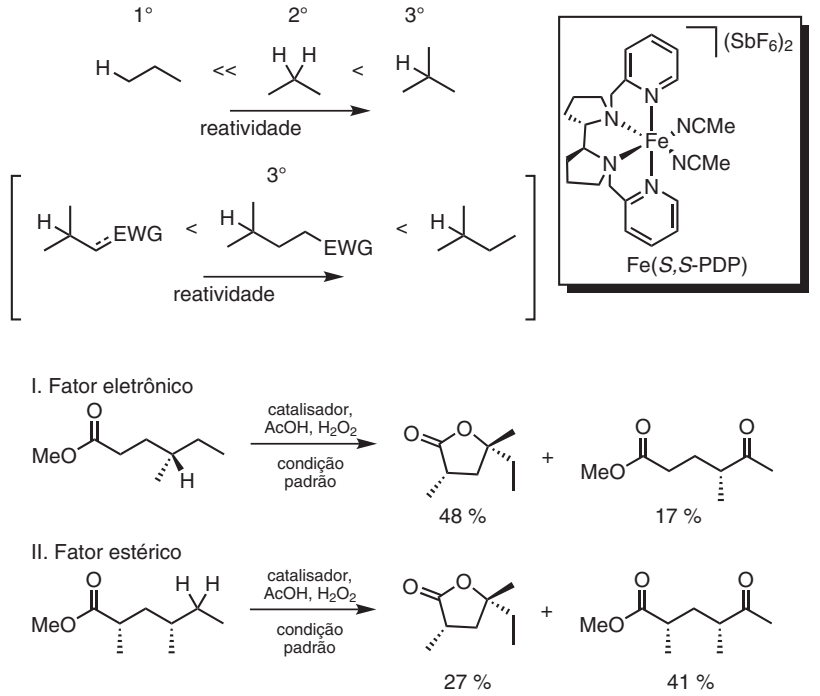

III. Oxidação dirigida

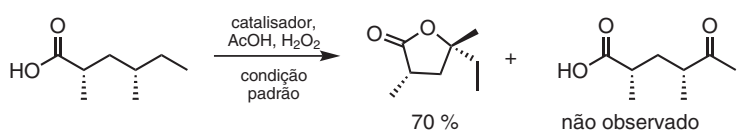

Condição padrão: $\mathrm{Fe}(S, S-P D P)$ (15 mol\%), $\mathrm{AcOH}$ (1,5 eq.), $\mathrm{H}_{2} \mathrm{O}_{2}$ (3,6 eq.), $\mathrm{MeCN}$, t.a., $30 \mathrm{~min}$

Esquema 19. Fatores que afetam a reatividade e a seletividade nas oxidações $C\left(s p^{3}\right)$-H terciárias catalisadas por $\mathrm{Fe}(\mathrm{S}, \mathrm{S}-\mathrm{PDP})$

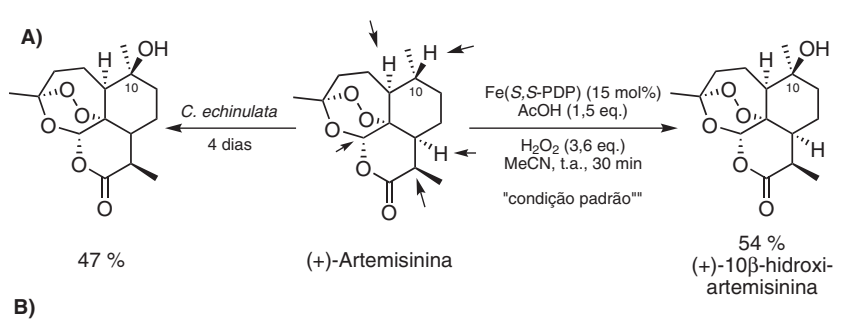

B)
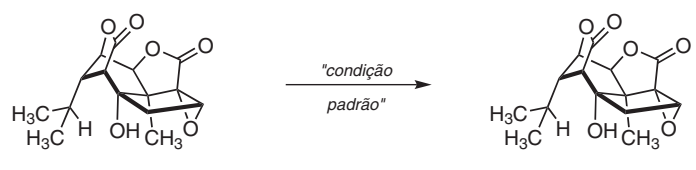

$(-)-\alpha$-diidropicrotoxinina

$92 \%$ do MP recuperado

C)

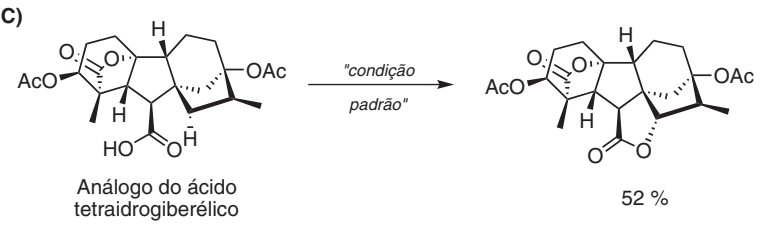

Esquema 20. Demonstração dos fatores que afetam as reações de oxidação $C\left(s p^{3}\right)$-H terciárias catalisadas por $\mathrm{Fe}(\mathrm{S}, \mathrm{S}$-PDP) em moléculas complexas

Por fim, um exemplo elegante de oxidação dirigida por um grupo carboxila foi relatado usando como substrato um análogo do ácido tetra-hidrogiberélico, no qual a ligação $\mathrm{C}-\mathrm{H}$ de um grupo metileno mais próxima do grupo carboxílico foi oxidado seletivamente em $52 \%$, levando à formação da lactona de cinco membros como um único diastereoisômero (Esquema $20 \mathrm{C}$ ).

A partir do observado neste primeiro trabalho, no qual grupos metileno são oxidados a cetonas, Chen e White ${ }^{68}$ estenderam este conceito a uma segunda geração desta metodologia. Baseando-se no fato de que as ligações $\mathrm{C}-\mathrm{H}$ de carbonos secundários são muito mais reativas que as de carbonos primários e de que a demanda estérica para os primeiros é menor que para carbonos terciários, os autores tiraram proveito desta reatividade intermediária para oxidar grupos metileno a cetonas seletivamente.

Os critérios estéricos e eletrônicos já elucidados no trabalho anterior se confirmaram também neste caso, com o adendo de que grupos capazes de doar densidade eletrônica ao orbital antiligante da ligação C-H (hiperconjugação) facilitam a oxidação do grupo metileno, pois o tornam mais rico eletronicamente. Os autores sugeriram também a existência de um fator estereoeletrônico presente na oxidação de anéis de seis membros substituídos com grupos volumosos (Esquema 21). Estes grupos, apesar de estarem em posição equatorial, aumentam a tensão torsional do sistema, aproximando as ligações $\mathrm{C}-\mathrm{H}$ em $\mathrm{C} 1$ e C3, incrementando as interações 1,3-diaxiais entre elas. Portanto, a oxidação em $\mathrm{C} 3$ é preferida em relação a $\mathrm{C} 4$, visto que esta causa alívio na tensão alílica 1,3 do sistema como um todo. Quando o cicloexano é substituído com um grupo éster este efeito se sobrepõe ao efeito indutivo retirador da carboxila e a oxidação em C3 mostra-se ainda preferencial em relação à oxidação em C4. Estas evidências preliminares, em conjunto com a maior seletividade observada para o substituinte terc-butila, corroboram a hipótese de que um componente esteroeletrônico influencie fortemente a regiosseletividade dessas reações.

IV. Fator estereoeletrônico

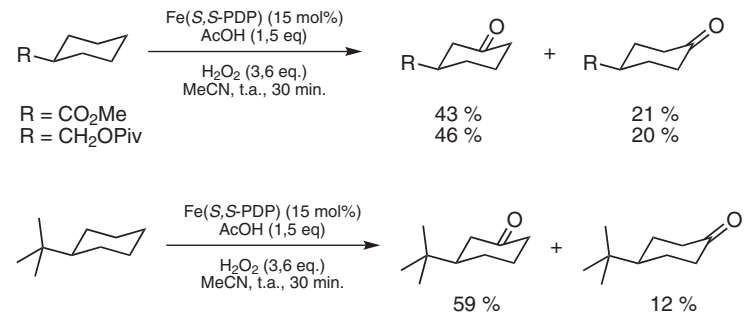

Esquema 21. Exemplo de efeito estereoeletrônico em reações de oxidação de grupos metilenos a cetonas

Embora os três fatores (eletrônico, demanda estérica e efeitos estereoeletrônicos) possam influenciar a reação, estes de forma isolada resultaram geralmente em seletividades modestas. Desta forma, os autores esperavam um efeito sinérgico destes três fatores para incremento da seletividade na oxidação de moléculas orgânicas estruturalmente mais complexas e observaram esta atuação cooperativa dos efeitos nos exemplos mostrados no Esquema 22. De forma geral, os autores escolheram compostos que demonstrassem a potencialidade da metodologia nos aspectos de rendimento e tempo reacional em comparação com oxidações enzimáticas, além de obterem para alguns casos regioquímica diferente da oxidação feita por enzimas.

A condição reacional elaborada nestes dois trabalhos de Chen e White consiste em um meio reacional oxidante e isto ainda traz limitações, como, por exemplo, a ausência de nitrogênio nos substratos empregados. Esta é uma ausência importante, visto que este elemento é praticamente onipresente no universo das moléculas bioativas. Contudo, os exemplos de oxidação apresentados nos Esquemas 19-22 não interferem na estereoquímica das moléculas usadas e caso a oxidação ocorra em um centro estereogênico, a configuração deste é mantida. Este último aspecto é valioso, pois assegura que a oxidação, de condições pouco brandas, pode ser usada no final de rotas sintéticas, sem prejuízo para a pureza óptica dos produtos. Esta oxidação em etapas próximas ao final da síntese, por sua vez, elimina do processo sintético um ponto reativo (oxigênio, nitrogênio, dupla ligação C-C, etc) dos substratos e diminui a possibilidade de 


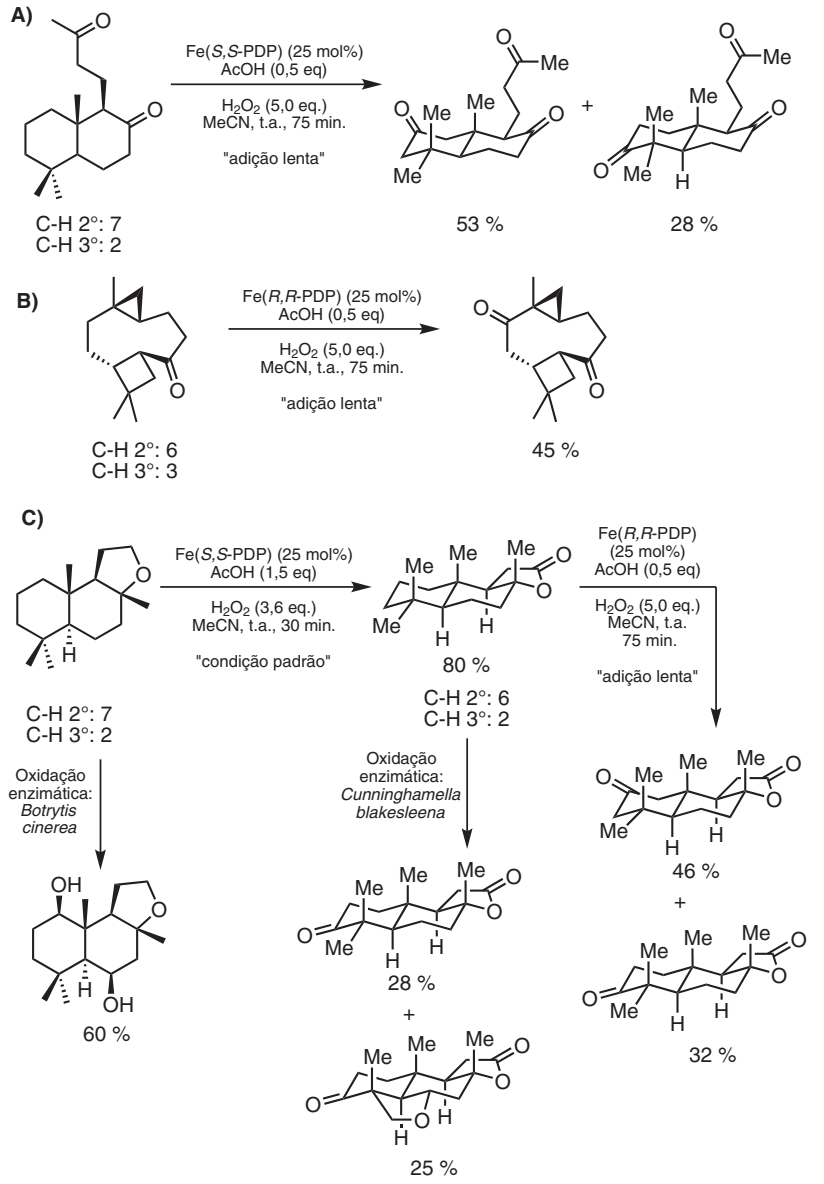

Adição lenta $=$ adição com injetor automático por $75 \mathrm{~min}$.

Esquema 22. Demonstração dos efeitos que afetam a oxidação de grupos metileno a cetonas em moléculas complexas e comparação com oxidações enzimáticas

reações laterais que têm o poder de deteriorar o rendimento global etapa após etapa. Da mesma forma, uma etapa de proteção e outra de desproteção são economizadas, das quais se deve incluir na fatura também a economia no isolamento e purificação, tanto em termos dos recursos utilizados como do tempo dispensado.

Estas ponderações mostram que a metodologia elaborada por Chen e White embora ainda incipiente, guarda um enorme potencial sintético. Colocar um oxigênio pontualmente em uma molécula com precisão cirúrgica e prever o ponto oxidado é uma ferramenta poderosa. Estender esta metodologia para a colocação de outros elementos, com o mesmo grau de precisão, é ainda um tanto utópico. No entanto, esta pequena ponta deste arsenal metodológico descoberta com clareza por Chen e White renova a possibilidade de se ter tais ferramentas ideais a serviço da síntese orgânica um dia. ${ }^{69}$

\section{INCERTEZA: O ATO DE FAZER E ADMIRAR OS PROCESSOS CATALÍTICOS EM SÍNTESE ORGÂNICA}

Ao longo deste texto, muito se demonstrou das façanhas até agora realizadas pela ativação de ligações $\mathrm{C}-\mathrm{H}$ e a maioria esmagadora das justificativas se impôs pelo aspecto econômico da síntese orgânica. ${ }^{70}$ Todavia, há uma maravilha escondida nestes entremeios que pede a palavra: a ligação $\mathrm{C}-\mathrm{H}$ é tratada como um grupo funcional com reatividade própria! $\mathrm{O}$ último exemplo comentado acima permite ainda questionar se as ligações C-C serão tratadas da mesma maneira algum dia. O real significado disto é que o quebra-cabeça está sendo desmontado, dado que um passo adiante só é possível se os métodos sintéticos catalíticos adentrarem o mundo subatômico. Em um futuro não tão distante, será possível montar/desmontar uma molécula carbono por carbono, átomo por átomo?

Também é prazeroso observar o trajeto de evolução da ciência Química e suas interconexões: a química inorgânica do século XX praticamente emerge da alquimia para o entendimento mais profundo dos complexos metálicos. Um número sem fim de métodos teóricos e práticos, assim como uma sistematização do conhecimento químico dos metais já foi em alguma extensão realizado. Desta odisseia, naturalmente, surgiu o entendimento de "interação agóstica", ${ }^{71}$ que é, por assim dizer, matriz dos atuais conhecimentos de quebra da ligação C-H catalisada por metais. Este conhecimento já passou pelos estágios de questionamento da comunidade acadêmica, de caracterização de diversos casos observados e de ajuntamento de dados para elaboração de modelos, para tornar-se ferramenta da Química contemporânea, especialmente da catálise e da química orgânica sintética. Esta evolução é clara, bela e muito elucidativa do modo como se constrói o conhecimento científico.

\section{REFERÊNCIAS E NOTAS}

1. Shilov, A. E.; Shul'pin, G. B.; Chem. Rev. 1997, 97, 2879.

2. Renaud, P.; Sibi, M. P., eds.; Radicals in Organic Synthesis; WileyWCH: Weinheim, 2001.

3. Gunay, A.; Theopold, K. H.; Chem. Rev. 2010, 110, 1060.

4. Beller, M.; Bolm, C., eds.; Transition Metals for Organic Synthesis; Wiley-VCH: Weinheim, 2004; Labinger, J. A.; Bercaw, J. E.; Nature 2002, 417, 507.

5. Kakiuchi, F.; Chatani, N.; Adv. Synth. Catal. 2003, 345, 1077; Guari, Y.; Sabo-Etienne, S.; Chaudret, B.; Eur. J. Inorg. Chem. 1999, 1047.

6. Godula, K.; Sames, D.; Science 2008, 312, 67.

7. http://nobelprize.org/nobel_prizes/chemistry/laureates/2010/, acessada em Julho 2011

8. Liu,B.; Qin, X.; Li, K.; Li, X.; Guo, Q.; Lan, J.; You, J.; Chem. Eur. J. 2010, 16, 11836.

9. Bia, J.-B.; You, S.-L.; Org. Lett. 2009, 11, 1187.

10. Os termos "(pré-)ativado" e "(pré-)funcionalizado" merecem esclarecimentos adicionais. Referem-se ao sítio reativo principal da molécula e não à substituição desta com outros grupos funcionais. Assim, os anéis aromáticos com substituintes são tratados como "anéis substituídos" e não como "funcionalizados". Por exemplo, um ácido borônico que serve para a reação de Suzuki-Miyaura é entendido como um substrato "(pré-)funcionalizado/ativado", pois seu sítio de reação não é uma ligação C-H. Além disso, o ácido borônico pode ser substituído com outras funcionalidades orgânicas (halogênios, ésteres, etc), mas em relação a estes substituintes, é tratado como um ácido borônico substituído.

11. Para um exemplo que pode ser comparado diretamente à ref. 8 , ver Malakar, C. C.; Schmidt, D.; Conrad, J.; Beifuss, U.; Org. Lett. 2011, 13,1378 .

12. Alberico, D.; Scott, M. E.; Lautens, M.; Chem. Rev. 2007, 107, 174; McGlacken, G. P.; Bateman, L. M.; Chem. Soc. Rev. 2009, 38, 2447.

13. Após a conclusão deste manuscrito, algumas revisões interessantes surgiram na literatura: Davies, H. M. L.; Du Bois, J.; Yu, J.-Q.; Chem. Soc. Rev. 2011, 40, 1855 (editorial da edição especial dedicada à funcionalização de ligações C-H); Newhouse, T.; Baran, P. S.; Angew. Chem., Int. Ed. 2011, 50, 3362.

14. Para outras contribuições recentes, ver Dong, V. M.; Yeung, C. S.; Zhao, X.; J. Am. Chem. Soc. 2010, 132, 5837; Daugulis, O.; Do, H.-Q.; Shabashov, D.; Acc. Chem. Res. 2009, 42, 1074; para arilação do indol, ver Joucla, L.; Djakovitch, L.; Adv. Synth. Catal. 2009, 351, 673; Hull, K. L.; Sanford, M. S.; J. Am. Chem. Soc. 2007, 129, 11904. 
15. Roy, D.; Mom. S.; Beaupérin, M.; Doucet, H.; Hierso, J.-C.; Angew. Chem., Int. Ed. 2010, 49, 6650.

16. Arockiam, P. B.; Fischmeister, C.; Bruneau, C.; Dixneuf, P. H.; Angew. Chem., Int. Ed. 2010, 49, 6629.

17. Liégault, B.; Lapointe, D.; Caron, L.; Vlassova, A.; Fagnou, K.; J. Org. Chem. 2009, 74, 1826 e referências citadas; Campeu, L.-C.; Fagnou, K.; Chem. Commun. 2006, 1253; o Prof. Keith Fagnou faleceu precocemente em 11/11/2009, vítima da gripe H1N1, http://cnews. canoe.ca/CNEWS/Canada/2009/11/12/11731241-sun.html, acessado em Julho 2011.

18. Stuart, D. R.; Fagnou, K.; Science 2007, 316, 1172.

19. Li, B.-J.; Tian, S.-L.; Fang, Z.; Shi, Z.-J.; Angew. Chem., Int. Ed. 2008 , 47, 1115

20. Produto originado da degradação do composto natural carbazomicina B: Crich, C.; Rumthao, S.; Tetrahedron Lett. 2004, 60, 1513.

21. Tsang, W. C. P.; Zheng, N.; Buchwald, S. L.; J. Am. Chem. Soc. 2005, 127,14560

22. Kawasaki, S.; Satoh, T.; Nomura, M.; Miura, M.; J. Org. Chem. 2003, 68, 6836.

23. Peña, D.; Castedo, L.; Pérez, D.; Guitián, E.; J. Org. Chem. 2000, 65, 6944; Peña, D.; Castedo, L.; Pérez, D.; Guitián, E.; J. Am. Chem. Soc. 1999, 121, 5827.

24. Gallo, R. D. C.; Rezende, H. V.; Muzzi, R. M.; Raminelli, C.; Quim. Nova 2009, 32, 2437.

25. Fukutani, T.; Hirano, K.; Satoh, T.; Miura, M.; Org. Lett. 2009, 11, 5198.

26. Wu, Y.-T.; Huang, K.-H.; Shin, C.-C.; Wu, T. C.; Chem. Eur. J. 2008, 14, 6697.

27. Para outros exemplos de reações envolvendo ativações C-H e alcinos, ver Shi, Z.; Zhang, B.; Cui, Y.; Jiao, N.; Angew. Chem., Int. Ed. 2010, 49, 4036; Gerfaud, T.; Neuville, L.; Zhu, J.; Angew. Chem., Int. Ed. 2009, 48, 572; Shi, Z.; Zhang, B.; Cui, Y.; Jiao, N.; Angew. Chem., Int. Ed. 2009, 48, 7895; Thirunavukkarasu, V. S.; Parthasarathy, K.; Cheng, C.-C.; Angew. Chem., Int. Ed. 2008, 47, 9462; Chernyak, N.; Gevorgyan, V.; J. Am. Chem. Soc. 2008, 130, 5636.

28. Lyons, T. W.; Sanford, M. S.; Chem. Rev. 2010, 110, 1147.

29. Rousseaux, S.; Gorelsky, S. I.; Chung, B. K. W.; Fagnou, K.; J. Am. Chem. Soc. 2010, 132, 10692.

30. Ackermann, L.; Chem. Rev. 2011, 111, 1315.

31. Gorelsky, S. I.; Lapointe, D.; Fagnou, K.; J. Am. Chem. Soc. 2008, 130, 10848.

32. Potavathri, S.; Pereira, K. C.; Gorelsky, S. I.; Pike, A.; LeBris, A. P.; DeBoef, B.; J. Am. Chem. Soc. 2010, 132, 14676.

33. Hull, K. L.; Sanford, M. S.; J. Am. Chem. Soc. 2009, 131, 9651.

34. Zhao, X.; Yeung, C. S.; Dong, V. M.; J. Am. Chem. Soc. 2010, 132, 5837.

35. Lapointe, D.; Fagnou, K.; Chem. Lett. 2010, 39, 1118.

36. Hartwig, J. F.; Tan, Y.; J. Am. Chem. Soc. 2011, 111, 3308.

37. Balcells, D.; Clot, E.; Eisenstein, O.; Chem. Rev. 2010, 110, 749.

38. Lewis, J. C.; Bergman, R. G.; Ellman, J. A.; Acc. Chem. Res. 2008, 41, 1013; Rech, J.; Yato, M.; Duckett, D.; Ember, B.; LoGrasso, P. V.; Bergman, R. G.; Ellman, J. A.; J. Am. Chem. Soc. 2007, 129, 490; Lewis, J. C.; Bergman, R. G.; Ellman, J. A.; J. Am. Chem. Soc. 2007, 129, 5332; O’Malley, S. J.; Tan, K. L.; Watzke, A.; Bergman, R. G.; Ellman, J.; A. J. Am. Chem. Soc. 2005, 127, 13496.

39. Martinez, R.; Simon, M.-O.; Chevalier, R.; Pautigny, C.; Genet, J.-P.; Darses, S.; J. Am. Chem. Soc. 2009, 131, 7887; Murahashi, S.-I., ed.; Ruthenium in Organic Synthesis, Wiley-VCH: Weinheim, 2004.

40. Zhang, L.; Cheng, J.; Ohishi, T.; Hou, Z.; Angew. Chem., Int. Ed. 2010, $49,8670$.

41. Referências com estes metais, utilizados com menor frequência podem ser encontrados nas revisões e artigos citados ao longo do texto. Por exemplos, as refs. 1, 5, 12, 13-16.
42. A ativação C-H é citada na comunicação de diversas empresas farmacêuticas como metodologias ambientalmente desejáveis: Dunn, P. J. et al.; Green Chem. 2007, 9, 411.

43. Para exemplos de ativação $\mathrm{C}\left(\mathrm{sp}^{2}\right)-\mathrm{H}$ e de alquilação/alquenilação de anéis heteroaromáticos não contemplados nesta revisão, ver Yao, T.; Hirano, K.; Satoh, T.; Miura, M.; Chem. Eur. J. 2010, 16, 12307; Wu, J.; Cui, X.; Chen, L.; Jiang, G.; Wu, Y.; J. Am. Chem. Soc. 2009, 131, 13888 .

44. Jazzar, R.; Hitce, J.; Renaudat, A.; Sofack-Kreutzer, J.; Baudoin, O.; Chem. Eur. J. 2010, 16, 2654.

45. Tsuchikama, K.; Kasagawa, M.; Endo, K.; Shibata, T.; Org. Lett. 2009, 11,1821

46. Guo, Y.; Zhao, X.; Zhang, D.; Murahashi, S.-I.; Angew. Chem., Int. Ed. 2009, 48, 2047

47. Liégault, B.; Fagnou, K.; Organometallics 2008, 27, 4841.

48. Para a alquilação de ligações $\mathrm{C}-\mathrm{H}$ alílicas, consulte: Jensen, T.; Fristup, P.; Chem. Eur. J. 2009, 15, 9632 (minireview); Young, A. J.; White, M. C.; J. Am. Chem. Soc. 2008, 130, 14090

49. Reed, S. A.; Mazzotti, A. R.; White, M. C.; J. Am. Chem. Soc. 2009, 131, 11701.

50. Rice, G. T.; White, M. C.; J. Am. Chem. Soc. 2009, 131, 11707.

51. Fraunhoffer, K. J.; Prabagaran, N.; Sirois, L. E.; White, M. C.; J. Am. Chem. Soc. 2006, 128, 9032.

52. Stang, E. M.; White, M. C.; Nature Chem. 2009, 1, 547.

53. Giri, R.; Shi, B.-F.; Engle, K. M.; Maugel, N.; Yu, J.-Q.; Chem. Soc. Rev. 2009, 38, 3242

54. Tran, D. N.; Cramer, N.; Angew. Chem., Int. Ed. 2010, 49, 8181

55. As referências 56-58 descrevem avanços significativos na área, os quais devem receber considerável atenção nos próximos anos: Peng, H. M.; Dai, L.-X.; You, S.-L.; Angew. Chem., Int. Ed. 2010, 49, 5826.

56. Para outro exemplo, ver: Albicker, M. R.; Cramer, N.; Angew. Chem., Int. Ed. 2010, 48, 9139.

57. Shi, B.-F.; Maugel, N.; Zhang, Y.-H.; Yu, J.-Q.; Angew. Chem., Int. Ed. 2008, $47,4882$.

58. Shi, B.-F.; Zhang, Y.-H; Lam, J. K.; Wang, D.-H.; Yu, J.-Q.; J. Am. Chem. Soc. 2010, 132, 460.

59. Emmert, M. H.; Gary, J. B.; Villalobos, J. M.; Sanford, M. S.; Angew. Chem., Int. Ed. 2010, 49, 5884; Arnold, P. L.; Sanford, M. S.; Pearson, S. M.; J. Am. Chem. Soc. 2009, 131, 13912.

60. Mikami, K.; Hatano, M.; Terada, M.; Chem. Lett. 1999, 55.

61. Beletskaya, I. P.; Cheprakov, A. V.; Chem. Rev. 2000, 100, 3009

62. Tietze, L. F.; Ila, H.; Bell, H. P.; Chem. Rev. 2004, 104, 3453; Dounay, A. B.; Overman, L. E.; Chem. Rev. 2003, 103, 2945; Shibasaki, M.; Boden, C. D. J.; Kojima, A.; Tetrahedron 1997, 53, 7371.

63. Davies, H. M. L.; Manning, J. R.; Nature 2008, 451, 417.

64. Davies, H. M. L.; Venkataramani, C.; Angew. Chem., Int. Eng. Ed. 2002, $41,2197$.

65. Takeda, K.; Oohara, T.; Anada, M.; Nambu, H.; Hashimoto, S.; Angew. Chem., Int. Ed. 2010, 49, 6979.

66. Ver informações suplementares da ref. 63 para um exemplo típico de procedimento experimental.

67. Chen, M. S.; White, M. C.; Science 2007, 318, 783.

68. Chen, M. S.; White, M. C.; Science 2010, 327, 566.

69. Sun, C.-L.; Li, B-L.; Shi, Z.-L.; Chem. Rev. 2011, 111, 1293.

70. Começam a surgir na literatura exemplos contendo também ativações de ligações C-C, além das ativações C-H. Para dois exemplos recentes, ver: Wang, C.; Rakshit, S.; Glorius, F.; J. Am. Chem. Soc. 2010, 132, 14006; Zhou, J.; Hu, P.; Zhang, M.; Huang, S.; Wang, M.; Su, W.; Chem. Eur. J. 2010, 16, 5876.

71. Brookhart, M.; Green, M. L. H.; Parkin, G.; PNAS 2007, 104, 6908. 